\title{
Kinetic parameters of the intrinsic reactivity of woody biomass and coal chars via thermogravimetric analysis
}

\author{
Khalidah Al-Qayim, William Nimmo*, Kevin Hughes and Mohammed Pourkashanian \\ Energy 2050 Group, Faculty of Engineering, University of Sheffield, S102TN, UK
}

\begin{abstract}
The available data on intrinsic kinetic parameters of wood char combustion is limited in the literature. The intrinsic reactivity of porous char particles reflects the variance in the pore structure resulted from various compositions of parent biomass or coal fuels. In this study detailed kinetic models for calculating the intrinsic reaction rate and the Arrhenius parameters in two combustion zones are developed for the char combustion. The influence of the parent fuel composition and the thermal treatment on the char oxidative reactivity observed on the char surface area and particle density are explored through a mathematical model of the char service area and density. A higher reactivity of the wood pellets than coal and enhanced reactivity with the increasing pyrolysis temperature were observed as well.
\end{abstract}

\section{KEYWORDS}

Intrinsic; Char; Kinetic; wood, Coal; TGA

\section{INTRODUCTION}

The combustion of solid fuel particles is a complex series of sequential and simultaneous reactions that can be classified in two major steps. The first step is the devolatilization of hydrocarbons and oxygen radicals (pyrolysis), supplemented by a profound change in the particle structure. The second step is the combustion of the solid porous residue (char) generated in the first step [1, 2].

Researchers have examined the biomass devolatilization products and many have developed reactivity models to calculate the kinetic parameters based on the three components classification (cellulose, hemicellulose and lignin). Biomass pyrolysis was described to a certain acceptable extent by a global irreversible first-order reaction, and the devolatilization rate is only a function of temperature [3-5]. However, the reaction can be demonstrated by more than one step and combines various species reactions. Agrawal [6] and Conesa et al. [7] found that the model proposed by Kilzer and Broido [8] (KBM) of wood pyrolysis had the best fitting with the TGA experimental data. The KBM assumes a sequence of reaction steps starting with the formation of anhydrocellulose $\left(\mathrm{Ce}^{*}\right)$ and tar then

"Corresponding Author: Dr. William Nimmo, Tel: 01142157213, Mob: 07818485631 w.nimmo@sheffield.ac.uk 
the intermediate $\mathrm{Ce}^{*}$ decomposes into volatiles and char. Mania et al. [9], Branca et al. [10], and Martin-Lara et al. [11] assumed three parallel non-interactive decomposition reactions of the three components (cellulose, hemicellulose and lignin) in sugarcane bagasse and waste wood with a first-order model for hemicellulose and cellulose, and a third-order model for lignin. However, it was found that Lignin decomposes at a wide range of temperatures that overlap with the other components [12].

The char reactivity is an imperative parameter of the simulation and process design of the combustion process due to the major contribution of the char oxidation to the heat value of the fuel. There are many rate law models used to explain the char combustion in the literature. The char combustion data were treated with Arrhenius model as a global n-order reaction of the oxygen pressure [13-17].

For the combustion of porous carbon particles, Essenhigh [18], assumes that the complex reaction occurs in a sequence of steps starting with the diffusion of oxygen through the stagnant boundary layer of nitrogen outside the particle to reach the external surface of the particle, chemisorption of oxygen on the external surface of the particle, internal (pore) diffusion, then further reaction of the remaining oxygen and carbon, and finally the diffusional discharge of the reaction products. The char is assumed a uniform sphere of carbon, and the reaction rate is the mass of carbon consumed per unit area, and proportional to the oxygen pressure. He represents the reaction rate as follows:

$R_{A}=-\rho_{p} \cdot \frac{d r}{d t}=-k \cdot P_{O 2}$

where;

$R_{A}$ : is the reaction rate, $\left(\mathrm{kg} \cdot \mathrm{m}^{-2} \cdot \mathrm{s}^{-1}\right)$

$r:$ is the particle radius, $(m)$

$\rho_{p}:$ is the particle density, $\left(\mathrm{kg} \cdot \mathrm{m}^{-3}\right)$

$k:$ is the specific reaction rate coefficient, $\left(s^{-1}\right)$

$P_{O 2}$ : is the oxygen pressure, $\left(\mathrm{kg} \cdot \mathrm{m}^{-2}\right)$

The Langmuir-Hinshelwood rate expression, assumes that the reaction rate is controlled by two kinetic mechanisms, first is a non-dissociative adsorption of oxygen particles on the carbon surface to form the complex $\mathrm{C}(\mathrm{O})$, and the second step is the desorption of $\mathrm{C}(\mathrm{O})[13$, $19,20]$.

$\mathrm{C}+\mathrm{O}_{2} \rightarrow C(O)$ ERROR! NO TEXT OF SPECIFIED STYLE IN DOCUMENT.

$C(O) \rightarrow C O$

In 2001, Hurt found that both the single step global model and the Langmuir-Hinshelwood model do not describe the reaction order data of char combustion [20]. Observations of $\mathrm{CO}_{2}$ 
forming in the reaction suggested the reaction of gaseous oxygen with the complex $C(O)$ as an intermediate step [21, 22]

$$
\begin{aligned}
& \mathrm{C}+\mathrm{O}_{2} \rightarrow \mathrm{C}(\mathrm{O}) \\
& \mathrm{C}(\mathrm{O})+\mathrm{O}_{2} \rightarrow \mathrm{CO}_{2}+\mathrm{C}(\mathrm{O}) \\
& \mathrm{C}(\mathrm{O}) \rightarrow \mathrm{CO}
\end{aligned}
$$

Thermal treatment of biomass and coal via a thermogravimetric analysis (TGA) has been extensively used to study the solid-phase burn-out rate [15, 21, 23-28]. Still, the intrinsic reactivity of biomass char combustion in comparison to coal has not gained enough interest and investigations in the literature. Also, the effect of the ash content on the pore surface area is not intensively highlighted in research work [29]. The intrinsic reactivity is the reaction rate per unit of total internal pore surface area per unit pressure of oxygen in the absence of any mass transfer limitations [30, 31].

In 1972, Smith \& Tylor [32] have formulated the relation between the apparent rate of reaction and the intrinsic reactivity for a first-order irreversible reaction of a porous solid as follows:

$R_{a c}=\eta \ddot{R}_{s} A_{g} \rho_{a} \gamma$

where;

$\eta$ : effectiveness factor $(\eta \leq 1)$.

It represents the actual chemical reaction rate as a fraction of the maximum rate possible on the total internal surface area of the particle [33]

In char combustion it is the fraction of the specific internal surface area $A_{g}$ necessary for reaction if the local intrinsic rate was identical to $\ddot{R}$ [31].

$\ddot{R}:$ Intrinsic rate for the hetrogeneous char reaction, $\left(\mathrm{kg}\right.$ carbon. $\left.\mathrm{m}^{-2} \cdot \mathrm{s}^{-1}\right)$

$A_{g}$ : Specific pore internal surface area, $\left(\mathrm{m}^{2} . \mathrm{kg}^{-1}\right)$

$\rho_{a}$ : appearant particle density, $\left(\mathrm{kg} \cdot \mathrm{m}^{-3}\right)$

$\gamma:$ the ratio between particle volume to particle surface area, $(m)$

Then, Smith [2, 30], and Laurendeau [31] have given the details of calculating the effectiveness factor from the Thiel modulus $\phi$ for first and n-order reactions of porous solids.

Equation (7) has been widely used in the modelling of coal char combustion and gasification in literature [34-39]. Adanez et al. [40] used the TGA data to predict the intrinsic kinetic parameters of wood chars and applied the kinetic parameters on the fluidized bed combustion boilers. Recently, Gao et al. [41] used the random pore model (RPM) to calculate the intrinsic reactivity of rice husk char gasification with $\mathrm{CO}_{2}$. They determined the intrinsic reaction rate constant as a function of the gasification temperature and the oxidant 
partial pressure. However, they assumed that gasification of the char at $950{ }^{\circ} \mathrm{C}$ is in the combustion zone I where there is no diffusion limitation. Therefore, they did not consider the effectiveness factor in the determination of the intrinsic reactivity. This assumption at such a high temperature does not comply with all the published data on combustion zone I that are reviewed by Smith [2].

The intrinsic reactivity of a char depends on three elements; 1 . Concentration of edge carbon atoms and dislocations, 2-mineral matter and trace elements, and 3- oxygen and hydrogen contents [31]. The overall reactivity also depends on the char porosity [42]. In addition, the char preparation conditions, i.e. heating rate, final pyrolysis temperature, and the residence time of the pyrolysis step, have a great effect on the produced char reactivity [43, 44]. The pyrolysis at low temperatures increases macropore size and decreases in the micro and mesoporous due to re-polymerization, particularly for plasticizing bituminous coals (high volatile matter content), and therefore increases the specific surface area of the char. While at higher pyrolysis temperatures the structural carbon crystallization increases, thus resulting in a lower concentration of the active sites [42, 43]. Similar conclusions were reached for anthracite coal due to the graphitization [45], and for sub-bituminous coal [46] due to the microporous blockage. Moreover, the char density increases with the increase of the heattreatment temp [47].

The work of this paper aims to evaluate the thermal behaviour of biomass at various devolatilization temperatures, and the reactivity of the biomass char combustion in comparison to coal. In addition, the intrinsic kinetic parameters and reactivity of the biomass char combustion are determined and evaluated in comparison to coal. Furthermore, the effect of the char preparation conditions, parent fuel composition, and ash content on the char reactivity are also investigated. Non-isothermal TGA data are used in the pyrolysis stage with the aim of producing chars at a certain temperature and burn them isothermally. Multiple sets of experiments are performed to produce char at different temperatures.

\section{MATERIALS \& EXPERIMENTAL METHODS}

Two types of wood pellets and two coal samples are used in this comparison. The biomass samples are the milled US white wood pellets (USWWP) imported by a power company in 2015, and the Canadian milled wood pellets (CAWWP) imported by E-ON company in 2014 . Both are mainly produced from soft wood parts such as spruce, fir and pine. The two coal samples used in this comparison are one from Vietnam-Hon gai region, which is infrequently studied in the literature (VC) and the other one is the Colombian coal El Cerrijon origin (ELC). These two types are the regularly imported types of coal to the UK. 
The proximate analysis measurements on as received (ar) fuels were performed according to the BSI standard methods BS EN ISO 18122, BS EN ISO 18123, and BS EN ISO 181341 using a Carbolite LHT6/30 furnace for ash content analysis and a Carbolite muffle furnace SCF 1100 for volatile matter content. The ultimate analysis on dry-ash-free (daf) basis, was performed with a Perkin Elmer flash2000 elemental analyser according to the BSI standard method BS ENISO 16948 to determine the $\mathrm{C}, \mathrm{H}, \mathrm{N}, \mathrm{S}$ of each sample. The proximate and ultimate analysis of the samples are given in Table 1. In contrast to the other three samples, the VC sample shows a significantly high ash content at $38.25 \%$ wt. The influence of this high percentage in ash content on the char reactivity is intensely discussed in this paper.

Table 1

Proximate and ultimate analysis of the selected fuels

\begin{tabular}{lrrrrr}
\hline Sample & M.C.\% & Ash\% & VM\% & FC\%* & GCV, kJ/kg \\
\hline USWWP & $5.48 \pm 0.26$ & $0.67 \pm 0.04$ & $86.32 \pm 0.61$ & 7.53 & $18,587 \pm 40$ \\
CAWWP & $6.37 \pm 0.40$ & $0.74 \pm 0.74$ & $84.51 \pm 0.97$ & 8.37 & $18,882 \pm 35$ \\
ELC & $3.96 \pm 0.08$ & $1.77 \pm 0.00$ & $44.48 \pm 0.25$ & 49.79 & $29,764 \pm 05$ \\
VC & $7.52 \pm 0.28$ & $38.20 \pm 0.14$ & $10.29 \pm 0.29$ & 43.99 & $21,883 \pm 62$ \\
\hline & $\mathrm{N}$ & $\mathrm{C}$ & $\mathrm{H}$ & $\mathrm{S}$ & $\mathrm{O}^{*}$ \\
\hline USWWP & $0.18 \pm 0.02$ & $49.34 \pm 0.24$ & $6.14 \pm 0.04$ & $<0.1$ & 44.04 \\
CAWWP & $0.76 \pm 0.01$ & $47.70 \pm 0.16$ & $5.05 \pm 1.10$ & $<0.1$ & 45.22 \\
ELC & $1.54 \pm 0.05$ & $76.41 \pm 0.60$ & $5.10 \pm 1.23$ & $<1.0$ & 15.08 \\
VC & $1.31 \pm 0.00$ & $92.57 \pm 1.12$ & $3.61 \pm 0.03$ & $<1.0$ & 2.20 \\
\hline
\end{tabular}

* determined by difference

\subsection{Sample Preparation For TGA}

Samples of $10 \mathrm{~g}$ were oven dried at $105^{\circ} \mathrm{C}$ for 4 hours and the weight is checked after the third hour every 20 minutes to ensure a constant weight is obtained. Then the samples are cooled in a desiccator and crushed in a mortar and pestle to homogenise them for sieving to less than $80 \mu \mathrm{m}$ particles, and stored in sealed containers for further analysis. The published studies have shown that in TGA experiments, the pulverized coal or biomass are within the particle size 63-100 $\mu \mathrm{m}[2,47-50]$. The small particle size is necessary for the TGA testing to ensure uniform heat distribution and gas diffusion within the sample particles, and to eliminate the effect of particle size on the rate of pyrolysis [51]. $5 \mathrm{mg} \pm 5 \%$ of each fuel type were used in the TGA tests to achieve consistency and uniform heat transfer throughout the sample particles.

\subsection{Thermogravimetric Analysis (TGA)}

The TGA experiments were performed with the Perkin-Elmer Pyris 1 TGA analyser in two steps. First, is the pyrolysis with an inert gas (nitrogen) to a certain temperature and hold 
the temperature constant until a steady weight is achieved, then the sample is subjected to air flow for the char combustion until a constant weight is obtained.

For pyrolysis step, pure oxygen-free nitrogen gas was used as the inert gas with a total flow rate $40 \mathrm{~mL} \mathrm{~min}{ }^{-1}$ at room temperature. The gas flowrate is controlled by a gas station control valve. Samples of $5 \mathrm{mg} \pm 5 \%$ were placed in a platinum pan of $5 \mathrm{~mm}$ diameter and $1 \mathrm{~mm}$ height in a 10-mm diameter furnace.

The nitrogen was kept purging the furnace for 20 minutes before the heating step to eliminate any air in the furnace tube and stabilize the balance reading. Then, the sample was heated to $110{ }^{\circ} \mathrm{C}$ and held for $20 \mathrm{~min}$ to remove any moisture, then heated to the final temperature at a constant heating rate of $100{ }^{\circ} \mathrm{C} \mathrm{min}^{-1}$. Iso-thermal conditions at the final temperature were continued until a steady weight was achieved. Afterwards, the purging gas was switched to air for char Combustion in the same flowrate and temperature. The test was ended when the final residue mass was constant. Tests were repeated twice for each operating condition.

This method of devolatilization followed by immediate char combustion without cooling and reheating to the combustion temperature is analogues to the proximate analysis of solid fuels used by Ottaway [52] to calculate the volatiles and char components of coal. Although, extensive research has been carried out on the coal char combustion treating the fuel in two separate steps; first, the devolatilization under an inert gas then cooling the produced char, reheat it under oxidizing conditions in different temperatures and gas pressure, the TGA experimental matrix is designed in a separate way in this study. The approach is to resemble the conditions demonstrated in the industrial scale of pulverized combustion where the fuel particles are devolatilized and combusted at the same time. In addition, the consistency of the devolatilization and the char combustion temperatures produces better prediction of the char structure alteration with temperature increase, and the cooling step effects on the char structure, is avoided.

\section{MATHEMATICAL MODEL OF THE CHAR COMBUSTION}

The char combustion rate obtained from the TGA data can be simply represented by the rate law of a single particle combustion as follows [2]:

$R_{m}=\frac{1}{(1-a)^{2}} \cdot \frac{d \alpha}{d t}=K_{o} \cdot\left[C_{o}\right]^{n}$

where;

$R_{m}$ : reation rate, gram carbon reacted per gram of original char per second. $\left(s^{-1}\right)$

$\alpha:$ fraction of dry - ash - free reactant carbon at time $t$.

$K_{o}$ : is the reaction rate coefficient, $\left(\mathrm{kg} \cdot \mathrm{m}^{-2} \cdot \mathrm{s}^{-1} \cdot\left[\cdot \mathrm{m}^{-3}\right]^{-n}\right)$ 
$\left[C_{o}\right]$ : bulk reactant gas concentration, $\left(\mathrm{kg} . \mathrm{m}^{-3}\right)$

$z, n:$ is the apparent reaction order for carbon and oxidant

$t$ : is the time, $(s)$

However, in order to understand the overall reactivity, the porous characteristics of the char requires the consideration of the local gas concentration on the external and internal surface area of the char pores. In addition to the diffusion limitations of the reactant gas through the boundary layer, the gas diffusion to the internal pore voids is another factor of the reaction rate to be considered. Thus, the true chemical reaction rate of the char combustion (the intrinsic rate), is the reaction rate per unit surface area of the internal or external pore surface area where there is no heat or mass transfer limitations [30].

In 1978, Laurendeau [31] described the global intrinsic surface reaction rate (per unit of surface area) $\ddot{R}$ as a function of the concentration of the carbon atoms per surface area of the pore and the local concentration of the oxidant gas as follows:

$\left.\ddot{R}=m_{c} \cdot r_{s}\left(\left[C_{t}\right] \cdot\left[C_{s}\right] \cdot T\right]\right)$

where,

$\ddot{R}:$ Intrinsic rate for the hetrogeneous char reaction, $\left(\mathrm{kg}\right.$ carbon. $\left.\mathrm{m}^{-2} \cdot \mathrm{s}^{-1}\right)$

$m_{c}:$ mass of carbon atom $\left(\mathrm{kg}\right.$ atom $\left.{ }^{-1}\right)$

$r_{s}:$ is the rate of conversion of carbon atoms from solid to gas (carbon atom. $\mathrm{m}^{-2} \cdot \mathrm{s}^{-1}$ )

$\left[C_{t}\right]$ : concentration of active carbon sites per unit area, $\left(\right.$ atom. $\left.m^{-2}\right)$

$\left[C_{s}\right]$ : local gas concentration, $\left(\mathrm{kg} \cdot \mathrm{m}^{-3}\right)$

If we approximate the carbon chemical rate as follows:

$r_{s}=k \cdot\left[C_{t}\right] \cdot\left[C_{s}\right]^{m}$

then, we obtain,

$\ddot{R}=m_{c} \cdot k \cdot\left[C_{t}\right] \cdot\left[C_{s}\right]^{m}$

$\ddot{R}=\ddot{K} \cdot\left[C_{s}\right]^{m}$

where,

$m:$ is the true reaction order

$k$ : chemical rate coefficient $\left(s^{-1}\right)$

$\ddot{K}:$ is the intrinsic rate coefficient $=m_{c} \cdot k \cdot\left[C_{t}\right],\left(\mathrm{kg} \cdot \mathrm{m}^{-2} \cdot \mathrm{s}^{-1} \cdot\left(\mathrm{kg} \cdot \mathrm{m}^{-3}\right)^{-\mathrm{m}}\right)$

The relation between the overall burn-out rate and the intrinsic rate on the particle surface $\ddot{R}_{S}$ is frequently expressed as follows [30, 31]:

$R_{m}=\left(\eta \cdot A_{g}+A_{e}\right) \cdot \ddot{R}_{S}$ 
Then we obtain

$R_{m}=\left(\eta \cdot A_{g}+A_{e}\right) \cdot \ddot{K} \cdot\left[C_{s}\right]^{m}$

where,

$\eta$ : effectiveness factor $(\eta \leq 1)$.

It represents the actual chemical reaction rate as a fraction of the maximum rate possible on the total internal surface area of the particle [33]

In char combustion it is the fraction of the specific internal surface area $A_{g}$ necessary

for reaction if the local intrinsic rate was identical to $\ddot{R}_{S}$ [31].

$A_{g}$ : Specific pore internal surface area, $\left(\mathrm{m}^{2} \cdot \mathrm{kg}^{-1}\right)$

$A_{e}$ : Specific external surface area, $\left(\mathrm{m}^{2} . \mathrm{kg}^{-1}\right)$

$\left[C_{s}\right]^{m}:$ is the gas concentration at the particle surface, $\left(\mathrm{kg} \cdot \mathrm{m}^{-3}\right)^{\mathrm{m}}$

In most cases $\eta . A_{g} \gg A_{e}$ then we obtain:

$R_{m}=\eta \cdot A_{g} \cdot \ddot{K} \cdot\left[C_{s}\right]^{m}$

The effectiveness factor is a function of the Thiele modulus $\emptyset$ and it can be calculated from the following relation [2]:

$\left[\frac{\eta \phi^{2} \cdot(m+1)}{2}\right]=\frac{\gamma \cdot R_{m}(m+1)}{\left[8 \cdot D_{e} \cdot C s\right]}$

where,

$\emptyset:$ Thiele modulus

$D_{e}:$ Effective diffusion coefficient, $\left(\mathrm{m}^{2} \cdot \mathrm{s}^{-1}\right)$

The right hand side of Eq. (16) can be calculated from the experimental data, then $\eta$ can be calculated from the relation between $\eta$ and $\eta \phi^{2}$ as derived by Mehta and Aris [31].

The effective diffusion coefficient is related to the overall diffusion coefficient of the gas through the particle internal and external surface area as proposed by Satterfield [53]:

$D_{e}=\frac{D \cdot \psi}{\tau^{2}}$

where,

$D$ : overall pore diffusion coeff.$\left(\mathrm{m}^{2} \cdot \mathrm{s}^{-1}\right)$

$\psi:$ particle porosity

$\tau^{2}:$ tortuosity $=(\sin \Omega)^{-1}$,

where $\Omega$ is the average angle of pore intersecting the external surface area.

It is assumed that $\Omega=45^{\circ}[31]$, hence, $\tau=\sqrt{2}$.

The overall diffusion coefficient $D$ is calculated according to the capillary diffusion of the single pore theory [31]. According to this theory, the oxygen diffusion through a single cylindrical pore comprises the molecular diffusion and Knudsen diffusion modes. Molecular diffusion $\left(D_{a}\right)$ is a function of both the temperature and pressure as in Eq. (18). The Knudsen 
diffusion $\left(D_{k}\right)$ characterizes the transport caused by the collision of oxygen atoms with the pore wall, and is given by Eq. (19). When the pore size is very small $(<1 \mu \mathrm{m})$, the Knudsen diffusion is predominant [2].

$D=\left(\frac{1}{D_{a}}+\frac{1}{D_{k}}\right)^{-1}$

$D_{a}=D_{o}\left(\frac{T}{T_{o}}\right)^{7 / 4} \cdot \frac{P}{P_{o}}$

where,

$D_{o}$ : molecular diffusivity at STP. $\left(\mathrm{m}^{2} \cdot \mathrm{s}^{-1}\right)$

$P$ : pressure (atm), and the denote (o)represent standard conditions

$D_{k}=\frac{\sigma}{3}\left(\frac{8 R T}{\pi \cdot M_{O 2}}\right)^{1 / 2}$

where,

$\sigma:$ pore diameter $(m)$

$R$ : universal gas constant $=8.314459\left(\mathrm{~kg} \cdot \mathrm{m}^{2} \cdot \mathrm{s}^{-2} \cdot \mathrm{mol}^{-1} \cdot \mathrm{K}^{-1}\right)$

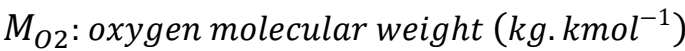

The pore mean radius $r_{p}$ can be calculated from the following equation [2]:

$r_{p}=2 \psi \tau^{0.5} / A_{g} \rho_{p}$

where,

$\rho_{P}$ : initial apparent density of char particle, $\left(\mathrm{kg} \cdot \mathrm{m}^{-3}\right)$

The surface concentration of the oxidant gas [Cs] can be calculated from the application of Fick's law to the boundary layer diffusion to calculate the overall mass transfer coefficient and it can be substituted into the overall particle reaction rate [31] to obtain the final relation as follows:

$R_{m}=\frac{12 \Lambda D_{a}}{\rho_{P} \cdot d_{p}^{2}}\left(C_{o}-C_{S}\right)$

$\therefore C_{S}=C_{o}-\frac{R_{m} \cdot \rho_{P} \cdot d_{p}^{2}}{12 \Lambda D_{a}}$

where,

$d_{P}$ : initial diameter of char particle, $(m)$

$\Lambda:$ gravimetric stoichiometric coefficient, $\Lambda=M_{c^{\cdot}}\left(v_{g} \cdot M_{g}\right)^{-1}$

$M_{c}, M_{g}:$ molecular mass of carbon and oxidizing gas, $\left(\mathrm{kg} \cdot \mathrm{kmol}^{-1}\right)$

$v_{g}:$ molar stoichiometric coefficient

For the char combustion the primary product is assumed to be CO therefore $\Lambda=3 / 4$. 
The char particle size and density vary with the type of the parent coal, the heating rate during devolatilization, and the combustion temperatures. The mass losses in the TGA samples are due either to the size reduction or density decrease. At any time in the char burn-off, we assume the particles are spherical;

$1-\alpha=\frac{d_{p}^{3} \rho_{p}}{d_{p o}^{3} \rho_{p o}}$

where the (o)denotes the initial state of the particle

$d_{P o}:$ initial diameter of char particle,$(m)$

$\rho_{P o}:$ initial density of char particle, $\left(\mathrm{kg} \cdot \mathrm{m}^{-3}\right)$

\subsection{COMBUSTION ZONE I}

It is established that in Zone I (the combustion occurs at temperatures below $900 \mathrm{~K}$ ) the reaction occurs with a deep penetration of oxygen to the internal pores due to the slow reaction at the lower temperatures [20]. Thus, the pore diffusion limitation is insignificant, and the rate coefficient $\ddot{K}$ is independent of the particle size [2, 14, 31, 54]. In this case $\eta=1(\varnothing \leq 0.5)$ and the oxygen concentration at the surface is equal to the bulk concentration $\left(C_{s}=C_{o}\right)$ and the value of $\ddot{K}$ and $\mathrm{m}$ can be calculated from the overall reaction rate as follows:

$R_{m}=A_{g} \cdot \ddot{K} \cdot\left[C_{s}\right]^{m}$

The apparent activation energy of the reaction characterizes the intrinsic (true) reactivity of the char particles. In support of this model, Adanez et al. [40] illustrated the effectiveness of this model in predicting the kinetic parameters of five wood species [40]. Also, Dupont et al. [29] expressed the kinetic reaction rate by calculating the activation energy $E_{a}$ of a reference sample and applied it to 21 samples of wood chips multiplied by an integral parameter that represents the differences between the wood species due to the mineral content of each one. They demonstrated that this parameter is linked to the ratio of the potassium/silicon content in the fuel.

\subsection{COMBUSTION ZONE II}

At high-temperature char combustion, where the reaction is under both the control of the chemical kinetic rate and oxygen diffusion rate to the pore walls, the effect of oxygen pressure and the particle size are both equally important. Thus both particle size and density are reduced [31]. The char pore structure is assumed to be large spherical vesicles with a porous structure on the walls [47]. The effectiveness factor decreases with increasing temperatures as the surface area available for the reaction decreases, hence $\eta=\frac{1}{\emptyset}$ for $\emptyset \geq$ 5.0. Essenhigh [55] approximated the Thiele modulus as follows: 
$\emptyset_{m}=\gamma \cdot\left[\frac{A_{g} \cdot \rho_{p} \cdot \ddot{K} \cdot C_{s}^{m}}{\Lambda \cdot D_{e} \cdot C_{s}}\right]^{1 / 2}$

Substituting $\eta$, and $\gamma=d_{p} / 6$ for spherical particles in Eq. (15), the overall reaction rate for Zone II becomes:

$R_{m}=\frac{6}{d_{p}}\left[\frac{\Lambda \cdot D_{e} A_{g} \cdot \ddot{K} \cdot C_{S}^{m+1}}{\rho_{p}}\right]^{1 / 2}$

From the experimental value of $R_{m}$ the intrinsic rate coefficient $\ddot{K}$ can be calculated.

This model combines the effects of particle size and the oxygen pressure on the overall rate of the char combustion. It can be seen from Eq. (27) that the overall particle reaction rate is inversely proportional to the particle size and to the square rout of the particle density. Laurendeau [31] reached the same conclusion for the combustion in Zone II. Essenhigh [55] also concluded that there is a negative dependence of the char combustion rate on the initial char density.

However, from the mathematical derivation of the rate model, the dependence of the intrinsic reaction rate $\ddot{R}$ and coefficient $\ddot{K}$ on the initial char density is negligible, and the reason for this is the inverse dependence of the effectiveness factor $\eta$ and the surface gas concentration $\mathrm{C}_{\mathrm{s}}$ on the particle density and thus these two effects cancel each other.

Comparing Eq. (25) and (27), the apparent order and activation energy can be related to the intrinsic values; $=\frac{m+1}{2}$, and $E_{a}=\frac{E_{t}}{2}$.

\section{CALCULATIONS OF THE CHAR PHYSICAL PROPERTIES}

The structural composition of biomass (cellulose, hemicellulose, lignin and ash) and the petrography of coal constituents (vitrinite, exinite and intertinite) determine the physical properties of the char produced, thus affecting its initial and evolved properties during char burn off. The physical properties, such as internal pore surface area, particle apparent density, true density, porosity, pore diameter, and particle diameter, are important to explain the char behaviour during combustion. The char specific surface area is a defining parameter of its intrinsic reactivity in the chemical control zone as shown in Eq. (25). Whereas, the other properties are important in the diffusion limitations zone as shown in Eq. (27). Moreover, those properties can be different for the same char produced at different temperatures.

Due to the experimental design of the TGA data in this study, it was difficult to have the char samples tested for their physical properties before the combustion step. Therefore, a review of the published experimental data on white wood and coal particles is performed to examine the change in physical properties of the char with the parent fuel composition and the char 
preparation temperature. Gan et al. [56] related the coal surface area $A_{g}$ to the carbon content of coal and found that the $\mathrm{CO}_{2}$ surface area decreases with an increase of $\mathrm{C} \%$ from 70 to $75 \%$ and then increases again with higher carbon content. However the $A_{g}$ values are not on one line but in a band of $80 \mathrm{~m}^{2} \mathrm{~g}^{-1}$. Chan et al. [47] plotted $A_{g}$ of three bituminous coal chars versus the char preparation temperature. They found that the minimum surface areas were of chars produced in the temperature range $773-973 \mathrm{~K}$. However, both correlations cannot be applied for all ranges of carbon content and temperatures.

Williams et al. [35] correlated the initial surface area of the coal chars produced at a temperature $1573 \mathrm{~K}$ in a drop tube reactor with the fixed carbon content of the parent coal and they found the following model:

$A_{g}=4764.2 C^{2}-7324.9 C+2912.9$

However, this model cannot be applied to the temperature range $773-973 \mathrm{~K}$ of this study as it is based on data of higher temperatures. Consequently, the published data of coal chars surface area in the literature were examined for correlation with the coal composition and the char preparation temperature. Data from Nandi [45], Harding et al. [57], Zhu et al. [44], Arenillas [58], Chan [47], Masnadi [59], and Williams et al. [35] were selected for the correlation of the coal char surface area with the temperature and the coal constituents.

The criteria for data selection were as follows: (a) the method of measurement was $\mathrm{CO}_{2}$ absorption, (b) the particle size close to the particle size of the samples in this study, (c) the char preparation temperature and method, and $(\mathrm{d})$ the temperature range $(773-1273 \mathrm{~K})$.

Figure 1 illustrates the dependence of coal char surface area on various parameters such as $\mathrm{C}_{\text {daf }}$, the ash $\mathrm{db}_{\mathrm{db}}$ and the $\mathrm{VM}_{\mathrm{db}}$ and the char preparation temperature. Interestingly, the data in Fig. 1-(a) shows a minor dependence of the specific char surface area $A_{g}$ with a wide range of the coal carbon content (daf), in the temperature range 773 to $1073 \mathrm{~K}$. The linear regression is poor and has only $0.075-0.647$ coefficient of determination R-Squared, and a low slope range of $-0.104-0.704$, whereas, at the temperature $1273 \mathrm{~K}$, the $A_{g}$ behaviour is completely different, as the $A_{g}$ trend is parabolic and has a minimum at carbon content 86$87 \%$. The regression $\mathrm{R}$-Squared is 0.598 , and the correlation equation at $1273 \mathrm{~K}$ is:

$A_{g}=9677.537-218.132 C_{d a f}+1.249 C_{d a f}^{2}$

Higher effect of the ash content on the $A_{g}$ can be observed in Fig.1-(b). The linear increase of $A_{g}$ with the ash content of the coal is more consistent in the temperature range 773-1173 $\mathrm{K}$, and it is shown in the high regression R-Squared at 0.946-0.999 with a higher slope range at 1.642- 1.807 , whereas, the behaviour of $A_{g}$ with the ash content at $1273 \mathrm{~K}$ is parabolic with $0.816 \mathrm{R}$-Squared and the correlation equation is as follows: 
$A_{g}=286.547-35.516 A s h+2.525 A s h^{2}$

Like the effect of carbon content, a trivial effect is observed on the $A_{g}$ with the increase of the VM content of the coal as can be seen in Fig. 1-(c). The linear regression has only $0.062-$ $0.535 \mathrm{R}$-Square, and a low slope range of $-0.339-0.056$, whereas, at the temperature 1273 $\mathrm{K}$, the $\mathrm{A}_{\mathrm{g}}$ trend can be assumed parabolic, with R-Squared 0.612 , and the correlation equation at $1273 \mathrm{~K}$ is:

$A_{g}=296.616-15.407 V M+0.348 V M^{2}$

Likewise, the preparation temperature effect on the $A_{g}$ is linear until $1173 \mathrm{~K}$, and then a sudden exponential increase or decrease occurs in the char surface area depending on the coal carbon content as shown in Fig. 1-(d).

These correlations suggest that at low temperatures until $1173 \mathrm{~K}$, the char preparation temperature and the ash content in the coal have the most significant effects on the char specific surface area, and at higher temperatures the carbon content is the leading parameter in the change of the char specific surface area.

In the case of biomass, data from Suliman et al. [60], Masnadi et al. [59], Lopez-Gonzalez et al. [61], Vallejos-Burgos et al. [62], Chowdhury et al. [61], and Abdul Halim \& Swithenbank [63], were also examined with the biomass composition and the temperature. In contrast to coal, the leading parameter is the volatile matter not the ash content, in addition to the char preparation temperature. This result can be explained by the high volatile matter content in wood that is released at lower temperatures than coal leading to a char with higher surface area and higher porosity.

Based on above observations, the published data were used to correlate the $A_{g}$ to the VM and the temperature in the case of biomass, and the ash content and temperature for coal using OriginPro 2017 to find a non-linear multivariable fitting function for the correlation. 

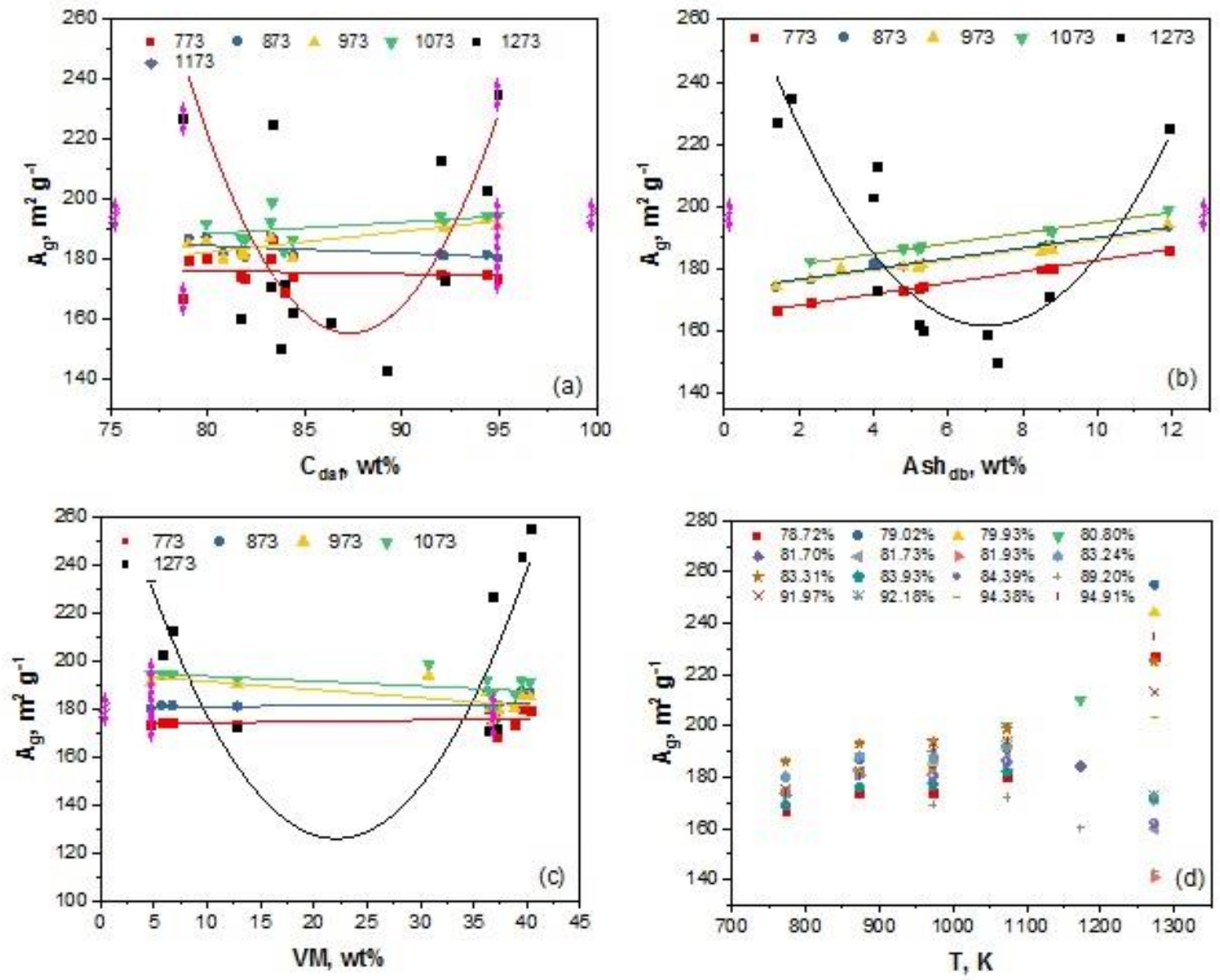

Fig. 1. Correlation of the char surface area to the composition of the parent fuel: (a) $\mathrm{C}_{\text {daf }} \%$, (b) ash content, (c) VM content, and (d) temperature.

In the same manner, data on the true and apparent densities of the coal char from Nandi et al. [45], Smith [64], Smith \& Tyler [32], Lu et al. [65], Matsuoka et al. [66], and Chan et al. [47], and data of the biomass char true and apparent densities published by Suliman et al. [60], Guo \& Lua [67], Vaughn et al. [68], Pastor-Villegas et al. [69] and other wood pellets data from the Energy research Centre of the Netherlands ECN database of biomass char [70-75] were selected to correlate the char apparent and true densities to the fuel composition and the temperature. As the carbon content is the major parameter that affects the density, data were plotted versus carbon content and temperature as shown in Fig. 2. Clearly, it can be seen from Fig. 2 that the true density of the coal char increases with both $\mathrm{C} \%$ and the temperature by a band of $1000 \mathrm{~kg} \mathrm{~m}^{-3}$, whereas, the influence on the char density of biomass is less evident and more random than on the coal char. The linear regressions in Figure 2-a prove this observation. The slope of coal char $A_{g}$ is $55.27 \pm 5.25$, whereas for biomass the slope is $15.46 \pm 6.95$. Also, the regression factor R-Squared is 0.834 for coal char and 0.553 for biomass. Figure 2-b shows linear regression for biomass char $A_{g}$ in a trivial slope of $0.837 \pm 0.5446$ and $\mathrm{R}$-Squared 0.371 . Again, the reviewed data were 
correlated to generate a multivariable function of the char density to the fuel constituents and the temperature, using OriginPro 2017 program.
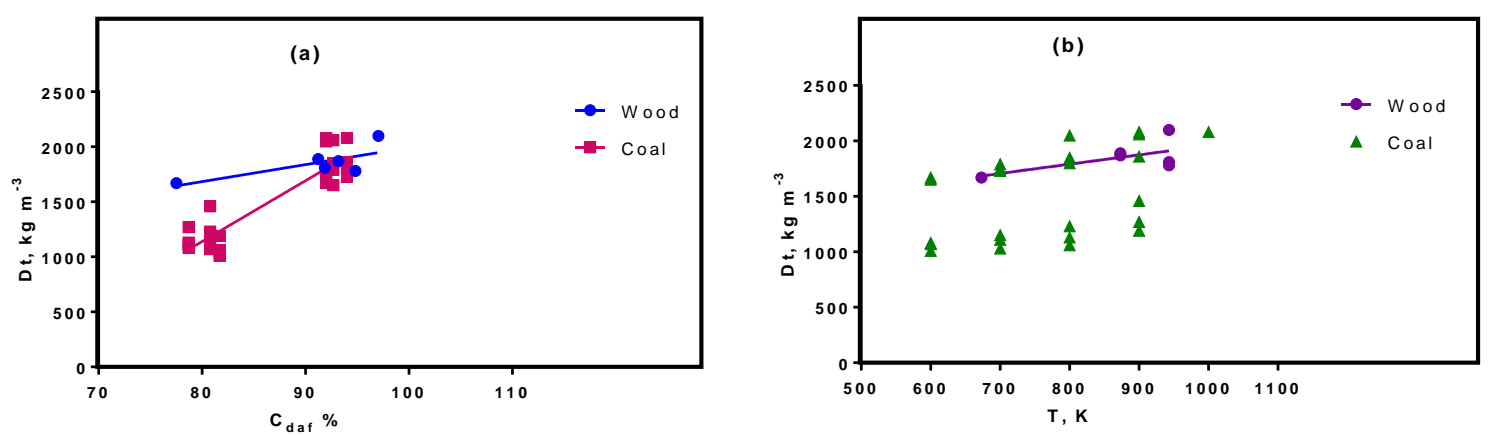

Fig. 2. Dependence of the true density of char on (a) C\% (daf), and (b) temperature.

\section{RESULTS \& DISCUSSION}

\subsection{CALCULATION OF CHAR PHYSICAL PROPERTIES}

\subsubsection{SPECIFIC SURFACE AREA}

For biomass char the best correlation of $A_{g}$ with $V M$ and the temperature was found, with an average error of $\pm 11.0 \%$, to be:

$A_{g}=1.65 V M^{1.13}+44 T^{0.5}-1248$

The sensitivity analysis showed that the leading parameter in the correlation is the temperature, with a $1 \%$ increase in Ag for every $10 \mathrm{~K}$ increase in the temperature. Also, the volatile matter is an important parameter as for every $1 \%$ increase in the $\mathrm{VM}$, the $A_{g}$ increases by $1 \%$.

Similar correlation attempt for the coal was performed, however, due to the change in the char structure at a temperature higher than $1073 \mathrm{~K}$, two correlations were found for the surface area of the coal char; one for the temperature region $773-973 \mathrm{~K}$ as in Eq. 2 with a \pm 13 .8\% error, and another correlation for the temperature region $1073-1273 \mathrm{~K}$ as shown in Eq. 3 with a $\pm 15.3 \%$ error:

$A_{g}=0.1 A s h^{0.7}+T^{0.07}+103$

$A_{g}=2.5 A s h^{0.89}+43 T^{0.5}-1370$

Yet in this case, the sensitivity analysis showed that $A_{g}$ of the coal char is more stable with the change of ash content and the temperature in the region of $773-973 \mathrm{~K}$, as such for every $10 \mathrm{~K}$ increase in temperature there is only a $0.4 \%$ increase in the $A_{g}$. Also, the ash content had insignificant effect on $A_{g}$, in which every $5 \%$ increase in the ash content, the surface 
area increases by $\pm 0.1 \%$. It was found that the carbon and the volatile matter contents had no significant effect on the char surface area. In contrast, at higher region of the temperature, the $A_{g}$ is highly sensitive to the ash content as for every $1 \%$ increase in the ash content, the $A_{g}$ increases by $2-4 \%$, and for every $10 \mathrm{~K}$ increase in the temperature results to a $5.0 \%$ increase in the $A_{g}$.

Equations (1), (2) and (3) were used to predict the char specific surface area of each sample used in this study at different temperatures.

\subsubsection{INITIAL CHAR TRUE DENSITY}

a correlation was derived for the true density of the char based on $\mathrm{C} \%$ (daf) and the preparation temperature. For biomass, the true density formula was found to be the following, with $\pm 4.76 \%$ error:

$\rho_{\mathrm{t}}=9750-386.0 C+4.221 T+3.70056 C^{2}+0.00221 T^{2}$

(Error! No

\section{text of specified style in document.35)}

As expected, the sensitivity analysis showed a higher dependence of the true density on the carbon content than the temperature. The true density of the biomass varies by $\pm(0.0-2.4 \%)$ for every $1 \%$ increase in the carbon content, whereas a $\pm 20 \mathrm{~K}$ change in the temperature results to a $\pm 1.5 \%$ change in the true density.

A similar equation was found for the coal data with a higher dependence on the carbon content with an error of $\pm 9.08 \%$ as follows:

$\rho_{\mathrm{t}}=3490-99.8 C-0.567 T+0.87496 C^{2}+0.00071 T^{2}$

(Error! No

text of specified style in document.36)

Like the biomass, the sensitivity of the coal char true density to the carbon content was higher than to the temperature. The true density increases by $3.5 \%$ with the carbon content increase of $1 \%$. On the other hand, the variance in the true density with temperature is like that of biomass, namely for every $\pm 20 \mathrm{~K}$ change in temperature the true density undergoes a $\pm 1.4 \%$ change.

\subsubsection{INITIAL CHAR APPARENT DENSITY}

Published data on the char apparent density were used to determine the dependence of the apparent char density with parent fuel carbon content and temperature. A non-linear multivariable function was generated by OriginPro 2017. The resultant correlation for biomass char, with $\pm 7.34 \%$ error is given as follows: 
$\rho_{\mathrm{A}}=11581-393.7 C+1.441 T+3.301 C^{2}-0.00059 T^{2}$

And, for coal char with a maximum $\pm 4.63 \%$ error:

$\rho_{\mathrm{A}}=10253-245.3 \mathrm{C}-0.085 \mathrm{~T}+1.5956 \mathrm{C}^{2}+0.00032 \mathrm{~T}^{2}$

Analogous to the true density, the apparent density showed a high dependency on the carbon content. The increase in carbon content of $1 \%$ resulted in a $3.7 \%$ increase in the apparent density, whereas for every $20 \mathrm{~K}$ variance in the temperature, only a $0.0-1.0 \%$ increase in the apparent density is witnessed. This result is in agreement with the findings of Chan et al. [47].

\subsubsection{Initial Char Particle Size}

Although the particle size has a great influence on the char properties [2, 14, 31, 64], it was difficult to correlate the char particle size to the fuel constituents due to the limited available data. In this study, the mean diameter of the char particles is determined from the relation between the degree of conversion (VM mass release) during devolatilization and the density, using equation (24):

The calculated initial physical properties of the four fuel chars are listed in Table 2.

Generally, the resultant values agree with the published data. For example, Zhu et al. [44] reported that the total surface area of the ELC sample at a temperature $1273 \mathrm{~K}$ as $227 \mathrm{~m}^{2} \mathrm{~g}^{-1}$. Compared to the correlation results in this study, of $192 \mathrm{~m}^{2} \mathrm{~g}^{-1}$, the variance falls within the expected 15.3\% error. Another example for coal char Ag, Arenillas et al. [58] measured the $\mathrm{CO}_{2}$ surface area of bituminous coals at $1123 \mathrm{~K}$ and found a range of $143-$ $151 \mathrm{~m}^{2} \mathrm{~g}^{-1}$ similar to the ELC result in this study at $1173 \mathrm{~K}$ of $159 \mathrm{~m}^{2} \mathrm{~g}^{-1}$. Ellis et al. [76] reported the specific surface area of the Canadian wood pellets char prepared at $1173 \mathrm{~K}$ at $468.1 \mathrm{~m}^{2} \mathrm{~g}^{-1}$, which is in agreement with the results of this study $\left(429 \mathrm{~m}^{2} \mathrm{~g}^{-1}\right)$. All the $\mathrm{Ag}$ results are within the expected range of char surface area, i.e. $100-600 \mathrm{~m}^{2} \mathrm{~g}^{-1}$, and the apparent density of the coal char is within the expected range of $900-1400 \mathrm{~kg} \cdot \mathrm{m}^{-3}$ [31]. However, neglecting the swelling/shrinking effect in the apparent density may affect the results of the density at the intermediate temperature range of $973-1073 \mathrm{~K}$. Therefore, the minimum/maximum limits of the calculated surface area were used to correct for this effect.

\section{Table 2}

Calculated initial physical properties of char at temperature range of $773-1273 \mathrm{k}$.

\begin{tabular}{|c|c|c|c|c|c|c|}
\hline & $\begin{array}{l}\mathrm{T} \\
\mathrm{K} \\
\end{array}$ & $\begin{array}{c}\mathrm{Ag} \\
\mathrm{m}^{2} \mathrm{~g}^{-1}\end{array}$ & $\begin{array}{c}\text { Apparent } \\
\text { Density } \\
\mathrm{Kg} \mathrm{m}^{-3}\end{array}$ & $\begin{array}{c}\text { True } \\
\text { Density } \\
\mathrm{Kg} \mathrm{m}^{-3}\end{array}$ & $\begin{array}{c}\text { Particle Size } \\
\text { m }\end{array}$ & Porosity \\
\hline \multirow{4}{*}{ USWWP } & 773 & 230 & 693 & 841 & 3.95E-05 & 0.18 \\
\hline & 873 & 306 & 883 & 986 & 3.73E-05 & 0.10 \\
\hline & 973 & 379 & 923 & 1151 & 3.61E-05 & 0.20 \\
\hline & 1073 & 448 & 963 & 1335 & 3.50E-05 & 0.28 \\
\hline
\end{tabular}




\begin{tabular}{rrrrrrr} 
& 1173 & 513 & 1003 & 1540 & $3.37 \mathrm{E}-05$ & 0.35 \\
& 1273 & 576 & 1043 & 1764 & $3.17 \mathrm{E}-05$ & 0.41 \\
\hline & 773 & 224 & 834 & 845 & $4.18 \mathrm{E}-05$ & 0.10 \\
& 873 & 300 & 874 & 990 & $4.00 \mathrm{E}-05$ & 0.12 \\
CAWWP & 973 & 373 & 914 & 1154 & $3.88 \mathrm{E}-05$ & 0.21 \\
& 1073 & 442 & 954 & 1339 & $3.72 \mathrm{E}-05$ & 0.29 \\
& 1173 & 507 & 994 & 1544 & $3.62 \mathrm{E}-05$ & 0.36 \\
& 1273 & 570 & 1034 & 1768 & $3.40 \mathrm{E}-05$ & 0.42 \\
\hline \multirow{6}{*}{ ELC } & 773 & 157 & 952 & 995 & $7.78 \mathrm{E}-05$ & 0.04 \\
& 873 & 164 & 997 & 1055 & $7.46 \mathrm{E}-05$ & 0.06 \\
& 973 & 171 & 1048 & 1130 & $7.29 \mathrm{E}-05$ & 0.07 \\
& 1073 & 178 & 1106 & 1219 & $7.10 \mathrm{E}-05$ & 0.09 \\
& 1173 & 185 & 1170 & 1322 & $7.07 \mathrm{E}-05$ & 0.11 \\
& 1273 & 192 & 1241 & 1439 & $6.98 \mathrm{E}-05$ & 0.14 \\
\hline \multirow{6}{*}{ VC } & 773 & & & & & \\
& 873 & 165 & 1390 & 1798 & $7.94 \mathrm{E}-05$ & 0.23 \\
& 973 & 172 & 1441 & 1872 & $7.73 \mathrm{E}-05$ & 0.23 \\
& 1073 & 179 & 1499 & 1961 & $7.67 \mathrm{E}-05$ & 0.24 \\
& 1173 & 186 & 1563 & 2064 & $7.54 \mathrm{E}-05$ & 0.24 \\
& 1273 & 233 & 1634 & 2181 & $7.40 \mathrm{E}-05$ & 0.25 \\
\hline
\end{tabular}

\subsection{PYROLYSIS BEHAVIOUR}

The complete thermal treatment profiles of the mass loss with time of the four samples are illustrated in Fig. 3. It can be seen from Fig. 3, that the biomass did not witness a meaningful change in the volatile matter (VM) release with the increase of the final pyrolysis temperature in the range $773-1273 \mathrm{~K}$. In contrast to biomass, ELC samples have clearly shown different mass losses with the temperature increase. Whereas, $\mathrm{VC}$ had a very small devolatilization step due to its low volatile matter content.

The DTG curves of the pyrolysis step of the four fuels are illustrated in Fig. 4. The USWWP and CAWWP DTG had onset temperatures at 603 and $588 \mathrm{~K}$, respectively, with a shoulder at $350{ }^{\circ} \mathrm{C}(623 \mathrm{~K})$. This shoulder is attributed to the hemicellulose decomposition. While the ELC onset is at a temperature $708 \mathrm{~K}$. On the other hand, the VC samples failed to release significant amounts of volatiles at a temperature $773 \mathrm{~K}$ independent of the pyrolysis time. Therefore, it was eliminated from the study. The VC onset temperature is found at $726 \mathrm{~K}$. The pyrolysis onset and peak temperatures are listed in Table 3.

\section{Table 3}

Pyrolysis characteristic temperatures of four fuels.

\begin{tabular}{|c|c|c|c|c|}
\hline Sample & Onset $\mathrm{T}$, & Peak T, K & $\begin{array}{r}\text { Peak end } \\
\mathrm{T}, \mathrm{K}\end{array}$ & $\begin{array}{r}\text { Peak degree of } \\
\text { conv. }(\alpha)\end{array}$ \\
\hline USWWP & 603 & 696 & 731 & 0.68 \\
\hline CAWWP & 588 & 693 & 728 & 0.67 \\
\hline EIC & 708 & 776 & 849 & 0.39 \\
\hline
\end{tabular}


0.51 

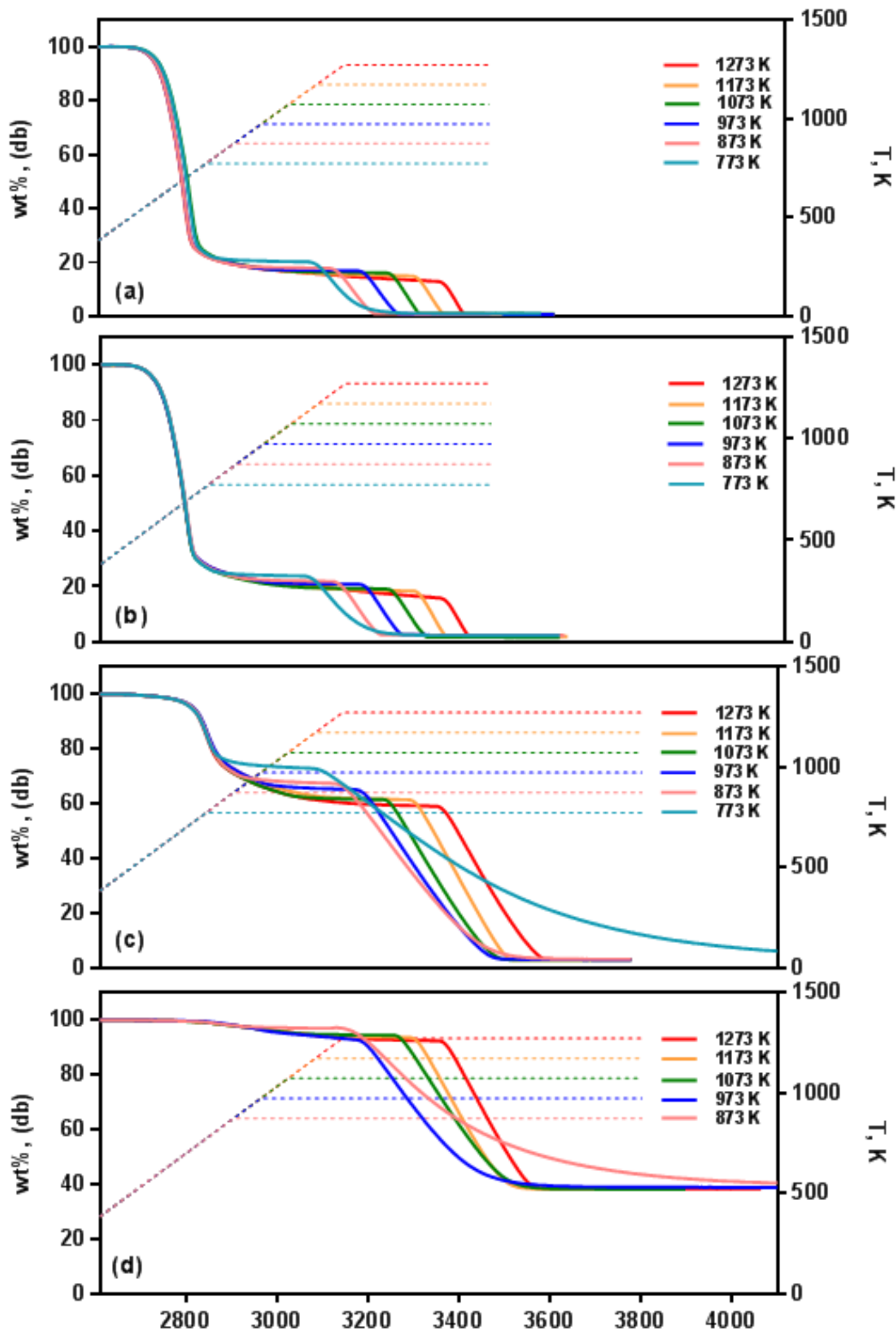

Fig. 3. TGA profile (wt\% vs. time) for non-isothermal pyrolysis up to the temperatures 773 , $873,973,1073,1173,1273 \mathrm{~K}$ in $40 \mathrm{~mL} / \mathrm{min} \mathrm{N}_{2}$ then iso-thermal char combustion step in $40 \mathrm{~mL} / \mathrm{min}$ air:(a) USWWP, (b) CAWWP, (c) ELC, and (d) VC. 

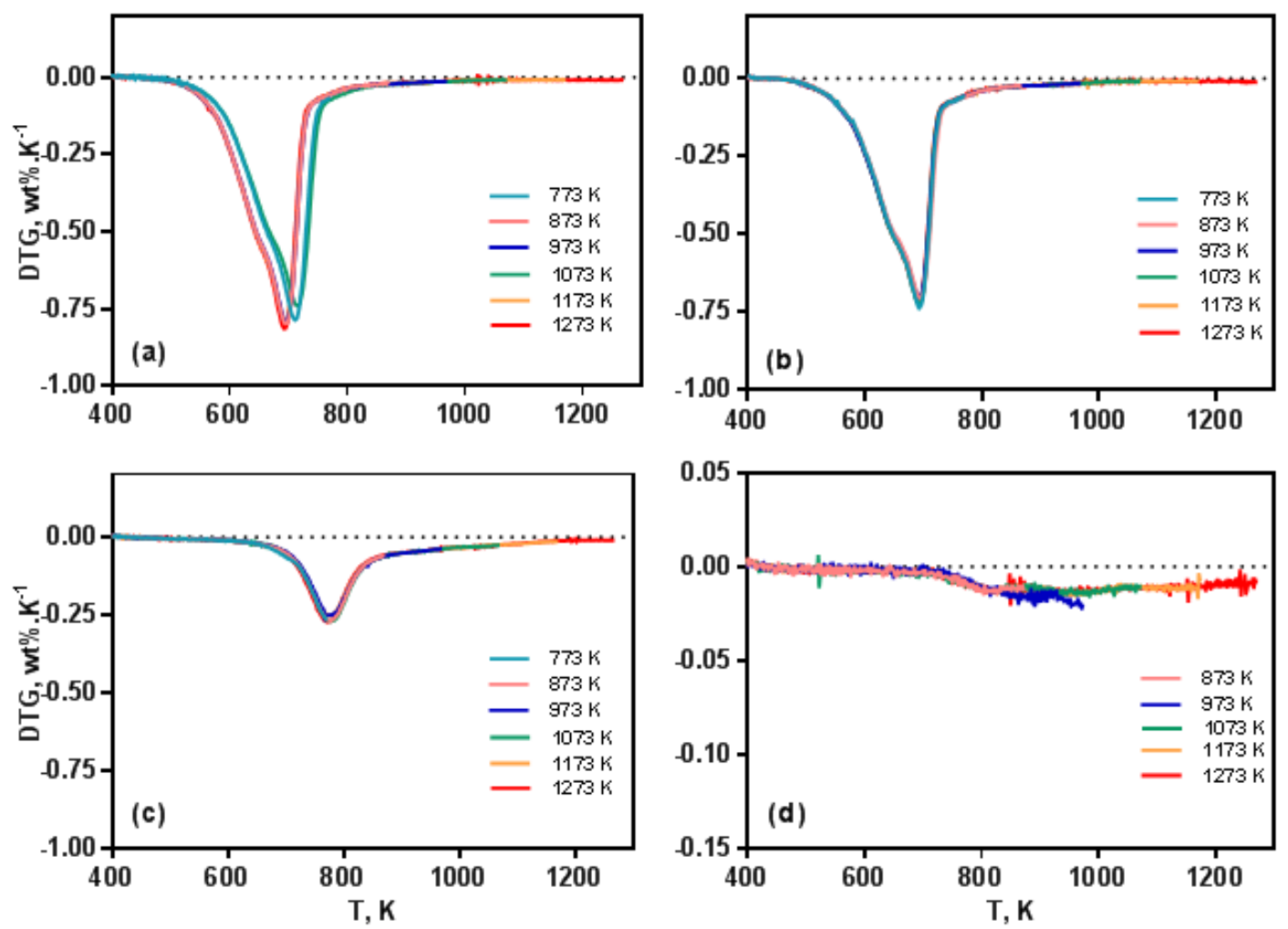

Fig. 4. DTG curves during the pyrolysis step $\left(w t \% \cdot \mathrm{K}^{-1}\right)$ of the four fuels heated to the temperatures $773,873,973,1073,1173,1273 \mathrm{k}$ in $40 \mathrm{ml}^{\mathrm{min}}{ }^{-1} \mathrm{~N}_{2}$ : (a)USWWP, (b)CAWWP, (c)ELC, and (d)VC.

\subsubsection{DEVOLATILIZATION YIELD}

Figure 5 illustrates the increase of VM yield with the temperature increase. As expected, the VM yield of the biomass during devolatilization is higher than the VM yield of the coal, and found to be $79-87 \% 76-84 \%, 27-41 \%$, and $3-8 \%$ for USWWP, CAWWP, ELC, and VC, respectively. The increase of volatile yield in both wooden biomass samples was $2 \%$ for every $100 \mathrm{~K}$ temperature increase. Whereas, the increase in both coal samples was $10 \%$ for the ELC and $33 \%$ for the VC, respectively.

These results suggest that biomass can release $90 \%$ of its VM at low temperatures. The higher release of VM from biomass species at lower temperatures compared to coal can be attributed to the difference in volatile matter composition in the two types of fuel. The linear chains of polysaccharides constituents of cellulose and hemicellulose, containing a high percent of oxygen and water content can be easily released in the temperature range 473 $673 \mathrm{~K}$. While the coal lamella consists of polynuclear aromatic, and hydroaromatic clusters linked together by aliphatic chains [31]. The aromatic clusters constitute $75 \%$ of the coal and they are responsible for the char formation. Whereas the hydroaromatic is $17 \%$ of the coal mass and this is responsible for the tar formation during pyrolysis. The aliphatic carbon 
chains are only $8 \%$ and produce $\mathrm{CH}_{4}, \mathrm{CO}$ and $\mathrm{CO}_{2}$ [77]. Therefore, coal requires higher temperatures to release heavier aromatic compounds during the devolatilization. This characteristic of the biomass gives more stability and higher reactivity during devolatilization step with less temperature dependence in the temperature range 800-1300 K. While for coal, a complete devolatilization occurs only at temperatures higher than $1273 \mathrm{~K}$.

On the other hand, the mineral content of the VC also differentiates the pyrolysis rate of the VC from the rate of the ELC pyrolysis. The higher mineral content, the more temperature sensitive is the devolatilization process. During pyrolysis, the mineral compounds are transformed to metal oxides in the char, forming ash component.

It can be argued, therefore, that the higher ash comprising coal faces mineral diffusion through the pores, causing resistance to the release of volatile matter due to the blockage of the pores and the devolatilization rate ultimately decreases. The failure of VC devolatilization in the temperature $773 \mathrm{~K}$ is an evidence to support this argument.

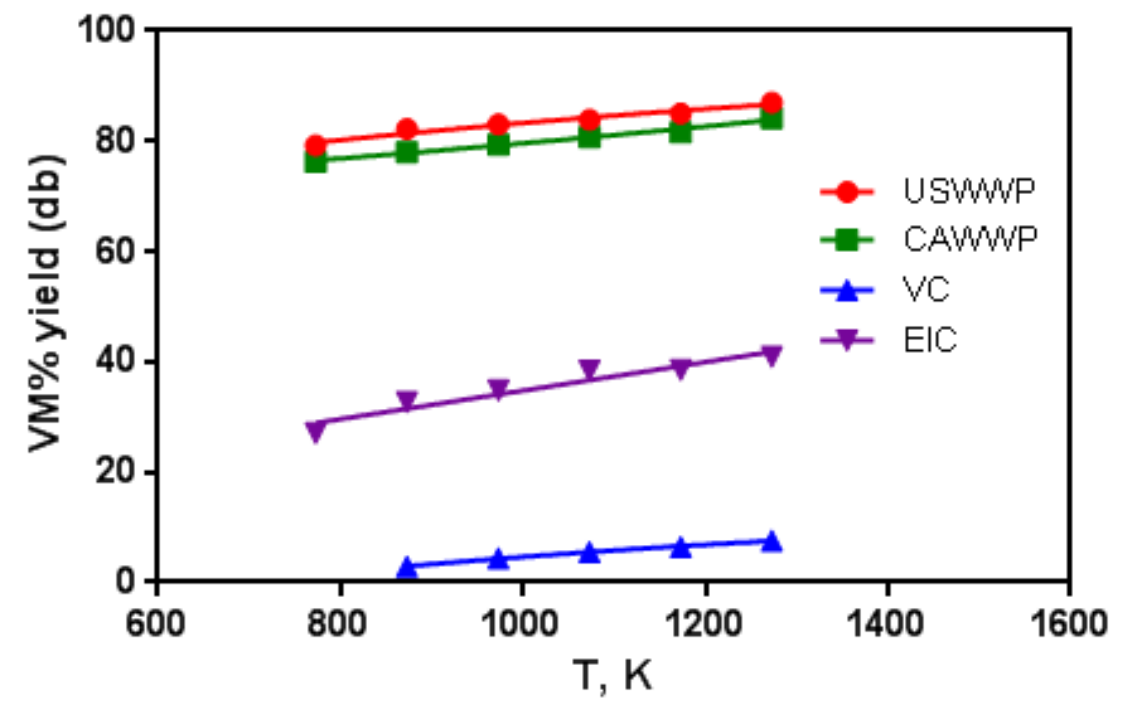

FIG. 5. Yield of volatile matter as a function of the pyrolysis temperature increase as mass $\%$.

\subsection{CHAR COMBUSTION BEHAVIOUR}

Figure 6 shows the DTG curves of USWWP, CAWWP, ELC and VC char combustion. In contrast to the devolatilization step, the increase in the char combustion rate of both biomass samples with the temperature increase is significant, as well as for the coal samples. The burn off rates of the four char samples at $1273 \mathrm{~K}$ are about twice the burn off rate at a temperature $773 \mathrm{~K}$. The four fuels showed single peaks with a wide area indicating complex steps of combustion of residual volatiles and carbon occurring simultaneously. Furthermore, the peaks at low temperatures have a long tail with a longer half-time than the peaks at the higher combustion temperatures. 

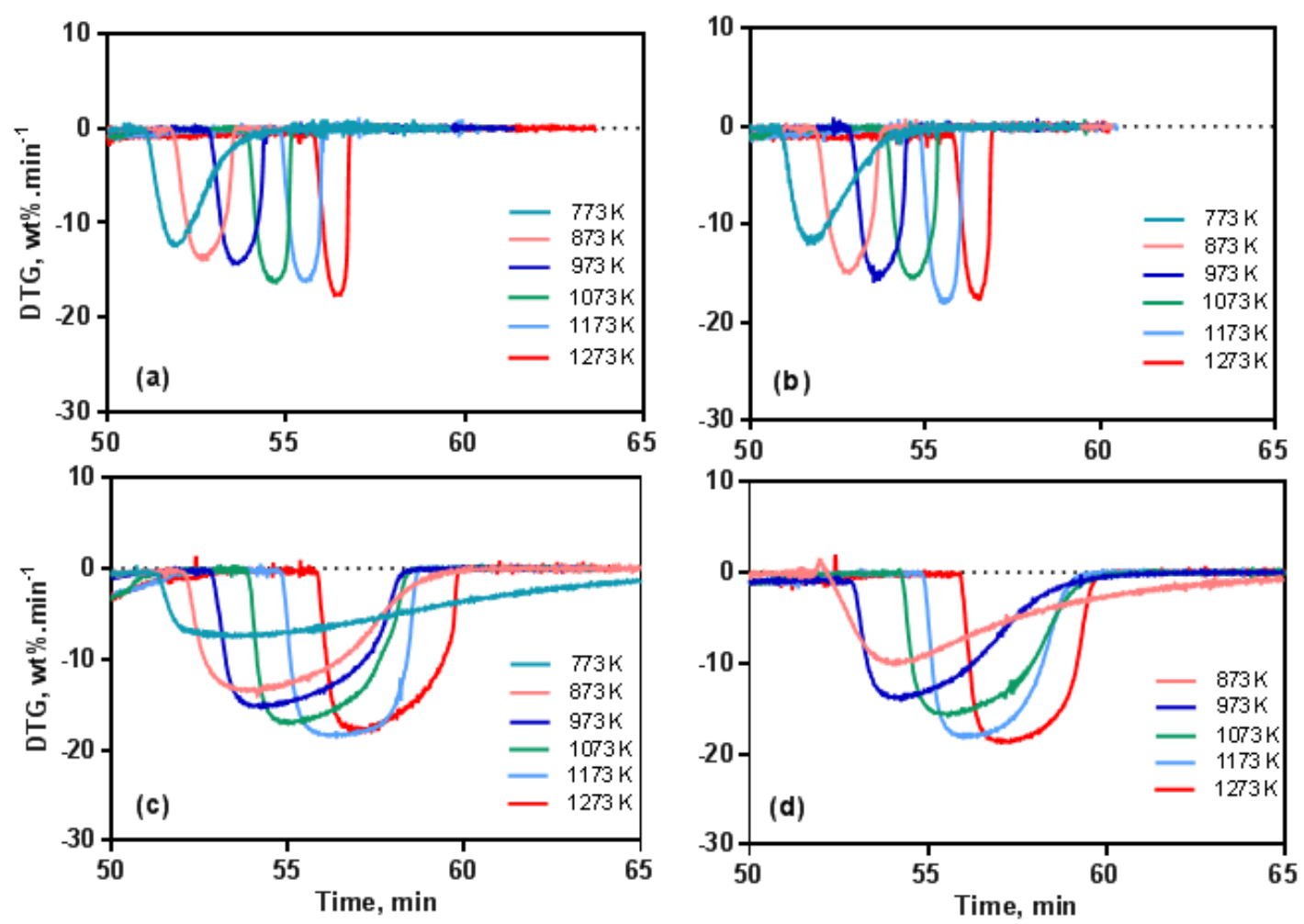

Fig. 6. DTG curves of the char combustion: (a) USWWP (b) CAWWP (c) ELC (d) $\mathrm{VC}$, at various combustion temperatures.

\subsubsection{CHAR BURN OFF RATE}

The fractional burn off $(\alpha)$ of the four fuel chars are calculated as dry-ash-free and plotted as a function of time in Fig.7. Clearly, both biomass chars have distinctly similar burn off rates in all combustion temperatures. Despite the alteration in their parent biomass compositions, it is likely that the pyrolysis step has eliminated the differences and produced very similar char behaviour. Moreover, both biomass chars needed the third of the coal chars time for a complete burnout in the temperature range of combustion. This indicates the higher burn off rates of biomass in comparison to coal.

To better understand the char combustion behaviour during burn off, the rate at which the burn off fraction $(\alpha)$ changes with the burn off progress for the four fuel samples, are plotted in Fig. 8. In general, the rate increases at the higher combustion temperatures at any degree of the burn off. At a temperature $773 \mathrm{~K}$ both biomass samples had the maximum burn off rate at $30-40 \%$ conversion. Whereas, both the ELC and VC had their maximum reaction rate at low conversions i.e. 20-30\%. Likewise, Fermoso et al. [17] reported the maximum reactivity of bituminous chars at $20-30 \%$ conversion. These results differs from that of Lizzio 
et al. [15] who found the maximum rate of bituminous char combustion at 30-40\% burn off. The reason for this dissimilarity, is the lower combustion temperatures ( $\leq 673 \mathrm{~K})$ in which the TGA experiments were performed in comparison to the temperatures of this work.

At higher temperatures, the burn off rate value becomes steadier for the range of $20-80 \%$ conversion. There is a sharp increase in the burn off rate within the first $5 \%$ burn off for all samples. One reason for this increase in the burn off rate is the quick combustion of the remaining aromatic hydrocarbons that eliminates the diffusional limitations, thus enabling the reactant gas to reach the smaller pores of the char particle. It was found that at temperatures higher than $1173 \mathrm{~K}$, the char micropores increase at the first stages of burn off due to the rapid destruction of the molecular sieve structure and the total surface area increases [78, 79]. On the other hand, thermal annealing starts at temperatures between 973 and $1373 \mathrm{~K}$, the micro porosity and carbon edges are lost, and the char structure becomes more graphitic, hence the active sites are lost [31].

It can be noticed from Figure 8, that at higher temperatures the burn off rate of VC char is higher than the ELC corresponding values despite the similar carbon (daf) content. This difference is due to the significantly higher mineral content that not only acts as a reaction catalyst but also inhibits the thermal annealing and graphitic structure formation by maintaining the dislocations and carbon edges, even at higher temperatures of combustion. In favour of this explanation is the work of Solomon et al. [80] on the crosslinking behaviour during the coal pyrolysis. They found that demineralization of lignite decreases the crosslinking reactions while the bituminous coals undergo early crosslinking during pyrolysis due to the presence of carboxyl groups. A recent study on pinewood char reactivity, Nanou et al. [81], enhanced the steam gasification reactivity by impregnation of ash into the wood char. It was found that the higher is the volatile matter content of a fuel, the higher is its char reactivity [82]. Similar conclusions are reported elsewhere in the literature $[17,83]$. 

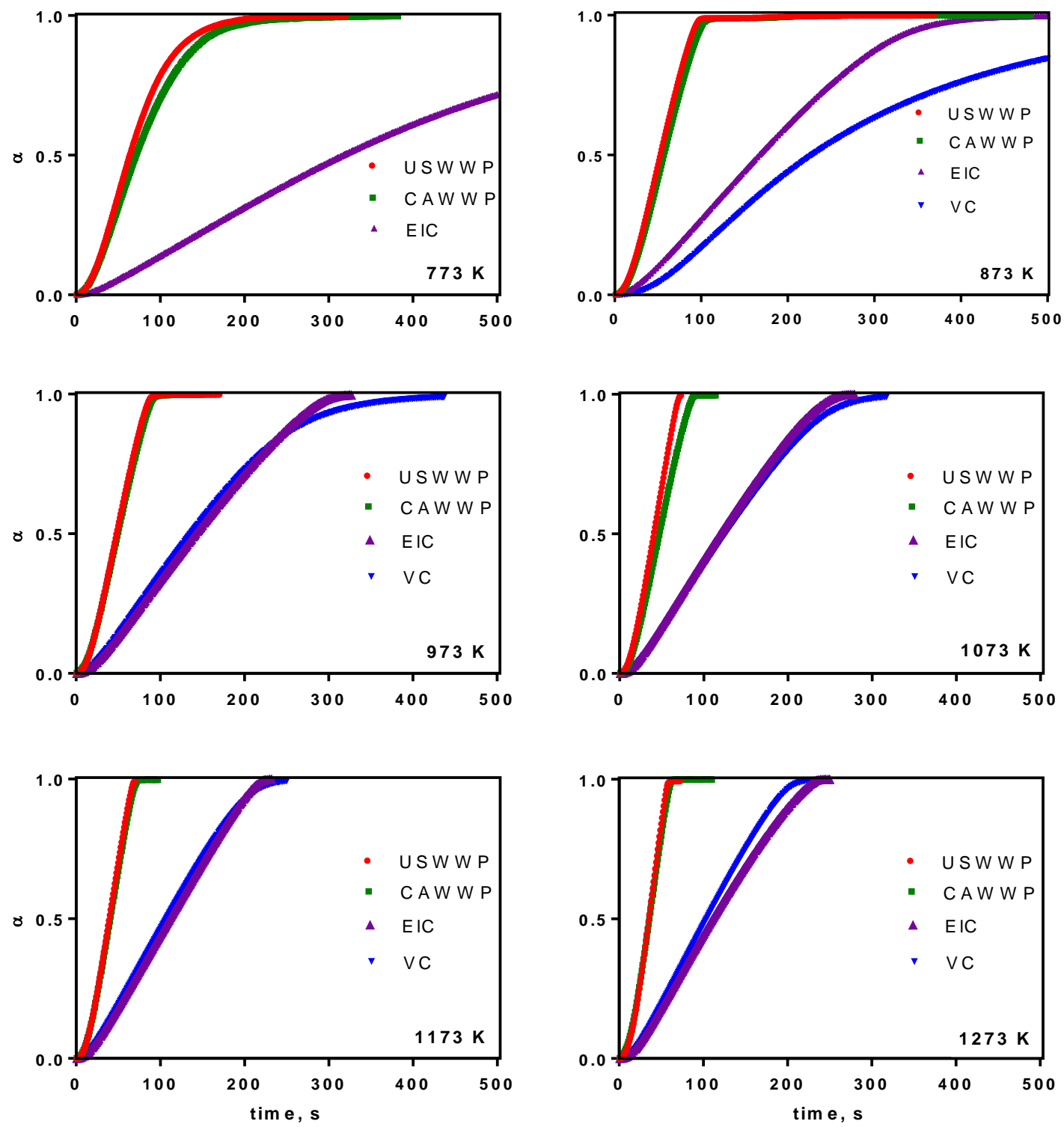

Fig. 7. Char fractional burn off $(\alpha)$ of USWWP, CAWWP, ELC and VC compared for each final pyrolysis temperature at $773,873,973,1073,1173$, and $1273 \mathrm{~K}$. 

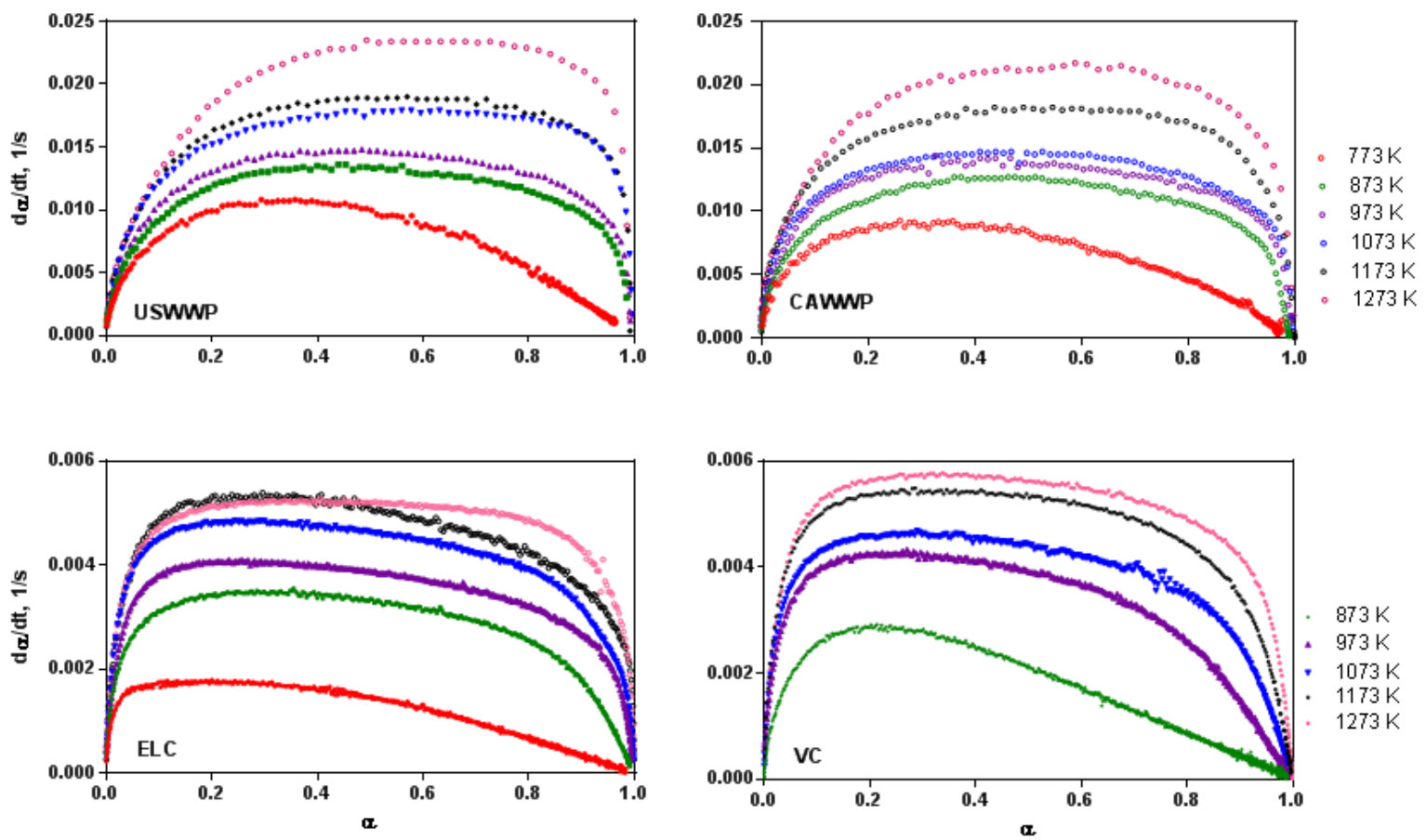

Fig. 8. Rate of fractional burn off change da/dt with the fraction of burn off $(\alpha)$, for the USWWP, CAWWP, ELC and VC in the temperature range 773-1273 K.

\subsubsection{REACTIVITY INDEX}

The reactivity index $\mathrm{RI}$ of the char oxidation rate is a parameter commonly used to compare the reactivity of different fuel chars [17]. The higher is the RI the higher char reactivity is:

$R I=\frac{0.5}{t_{0.5}}, \frac{1}{s}$

where, $t_{0.5}$ is the time of $50 \%$ carbon burn out.

The reactivity index values of the char oxidation at 0.2 oxygen partial pressure and temperature range $773-1273 \mathrm{~K}$ are listed in Table 4 , with $\pm 3 E-4$ average uncertainty. As expected, the reactivity index of the biomass samples is higher than those of the coal samples. The USWWP and CAWWP have increased RI values from 0.008 and $0.007 \mathrm{~s}^{-1}$ at a temperature $773 \mathrm{~K}$ to 0.015 and $0.014 \mathrm{~s}^{-1}$ at $1273 \mathrm{~K}$, respectively. The RI values of both coal samples increases more quickly, however they show less variability in temperatures above $973 \mathrm{~K}$ and increase from 0.002 to $0.005 \mathrm{~s}^{-1}$. 
Table 4

Reactivity index $(\mathrm{RI})$ at 0.2 oxygen partial pressure and temperature range 773 $1273 \mathrm{~K}$.

\begin{tabular}{|c|c|c|c|c|}
\hline \multirow[b]{2}{*}{$\mathrm{T}, \mathrm{K}$} & \multicolumn{4}{|c|}{$\mathrm{RI}, \mathrm{s}^{-1}$} \\
\hline & USWWP & CAWWP & EIC & VC \\
\hline 773 & 0.00794 & 0.00704 & 0.00158 & \\
\hline 873 & 0.00962 & 0.00893 & 0.00301 & 0.00220 \\
\hline 973 & 0.01064 & 0.01020 & 0.00354 & 0.00370 \\
\hline 1073 & 0.01250 & 0.01087 & 0.00420 & 0.00403 \\
\hline 1173 & 0.01316 & 0.01250 & 0.00450 & 0.00472 \\
\hline 1273 & 0.01471 & 0.01429 & 0.00454 & 0.00485 \\
\hline
\end{tabular}

Figure 9 shows the reactivity index variation with temperature. The trend $\mathrm{RI}$ increasing with the temperature can reveal the reactivity zones. From Figure 5-11, it can be observed that the biomass samples have Zone I reactivity in the temperature range of $773-873 \mathrm{~K}$, then an intermediate zone at $873 \mathrm{~K}-1173 \mathrm{~K}$ for the USWWP, and 873-1073 $\mathrm{K}$ for the CAWWP, and finally Zone II at $1173-1273 \mathrm{~K}$. In a separate way, the coal samples show a first reactivity zone in the temperature range $773-973 \mathrm{~K}$, and then two steady reactivity zones between 973-1073 K and 1173-1273 K. These results can only be confirmed by the results of the char oxidation reaction kinetic parameters that are calculated in section 5.3.4.

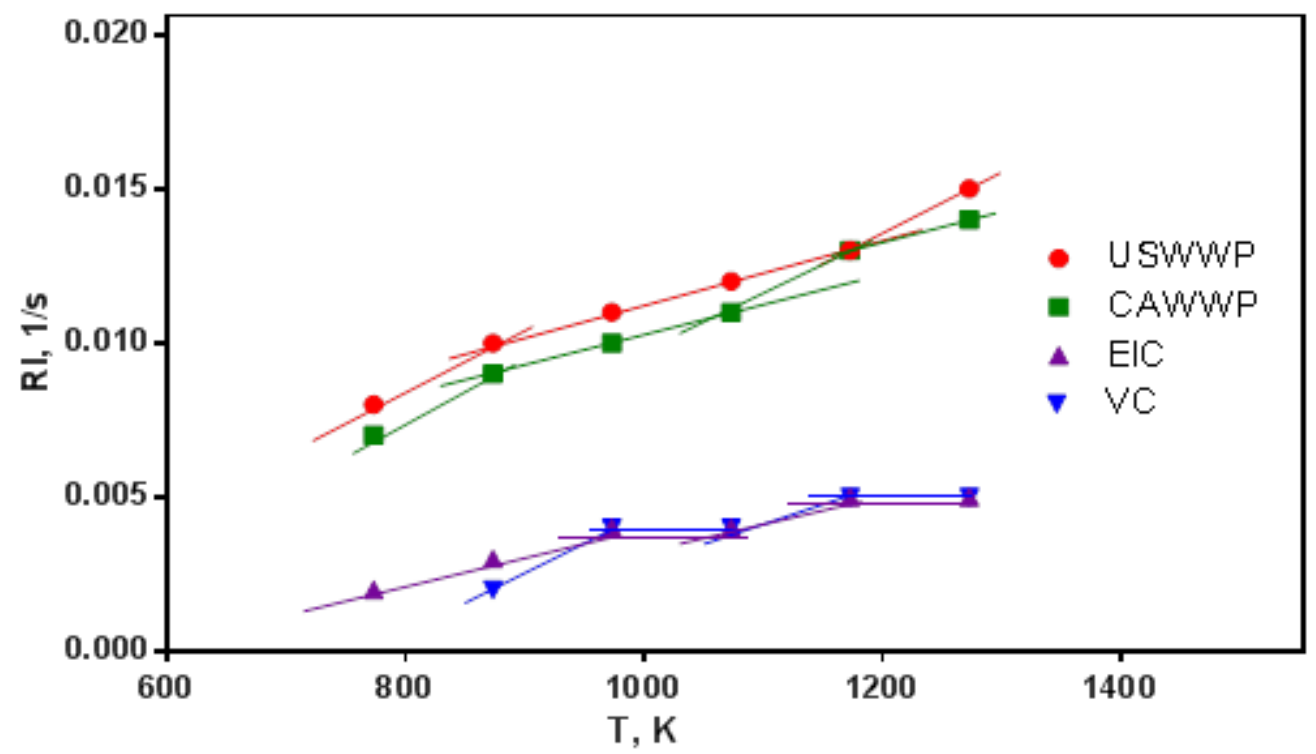

Fig. 9. Reactivity index of USWWP, CAWWP, ELC and VC at 0.2 oxygen partial pressure and variable temperatures 


\subsubsection{INTRINSIC CHAR REACTIVITY}

The derived intrinsic reactivity model in section 3 for the char combustion is applied on the set of isothermal experiments to calculate the intrinsic reaction rate and the Arrhenius triplet (activation energy, pre-exponential factor and the reaction order) of char combustion.

The overall reaction rate $R_{m}$ was calculated according to Eq. (8) from the TGA data range of the peak conversion. Then the global intrinsic reaction rate coefficient $\ddot{K}$ was calculated according to Eq. (27) and the Arrhenius rate constant $(k)$ is calculated from Eq. (11). The Arrhenius plots of $\ln (k)$ as a function of the temperature reciprocal $\mathrm{T}^{-1}$ are shown in Fig.10.

Significantly, all the fuel types have exhibited more than one linear region. These regions are correlated by linear functions with least square coefficients $\geq 0.90$. The biomass samples exhibited three regions of reactivity; and, the coal samples have shown mainly two regions. Never the less, all the samples had the same reactivity in the temperature region 773-873 K, and this is an unmistakable evidence of chemically controlled reactivity in the combustion Zone I. In the temperature range $873-973 \mathrm{~K}$, the biomass samples exhibited a considerable change in reactivity, in which the higher porosity resulting from the pyrolysis step increases the char surface area and ultimately increases the char reactivity. By contrast, the coal char samples exhibit a continuous behaviour in the temperature range $773-973 \mathrm{~K}$, and this is because of the suggestively lower surface area than in the biomass.

As shown in section 4.3.2, the reactivity of the coal chars is lower than that of the biomass char. In that order, the intrinsic reactivity of combustion Zone II of the coal char is lower than the intrinsic reactivity of the biomass char, however, tending to exceed the biomass reactivity at higher temperatures than $1273 \mathrm{~K}$ (combustion Zone III), where the diffusion limitations dominate the reaction rate $[2,20,31]$.

Interestingly, the dependence of the intrinsic reactivity on the initial particle density, whether apparent or true, is proved to be negative through the calculations. This finding supports the argument made earlier in Section 3.2.

\subsubsection{ARRHENIUS KINETIC PARAMETERS}

The reaction order for oxygen in the temperature Zone I (773-873 K) was assumed to be 0.5 -order for all samples. In the case of the VC, the sample failed to devolatilise at $773 \mathrm{~K}$ due to its high ash and low volatile matter contents, however at a temperature $873 \mathrm{~K}$ the reaction order was 0.5 . This assumption is based on the published data that assumes the intrinsic reaction order value is between $0.5-1.0$ for Zone I combustion [20, 64]. The reaction order of char combustion rate in Zone II was assumed to be first-order as reported 
in the literature for the chars of various coal ranks [2], and assumed to be first-order in the absence of experimental data [30]. Young \& Smith [84] experimentally found a value of $\mathrm{n}=0.4$ for the char combustion at a steady-state flow combustor in a temperature range of 940-1420 K (combustion Zone II). However, the discrepancy of these results with the assumption in this study can be explained by the effect of the transport phenomena that is eliminated in the TGA kinetics.

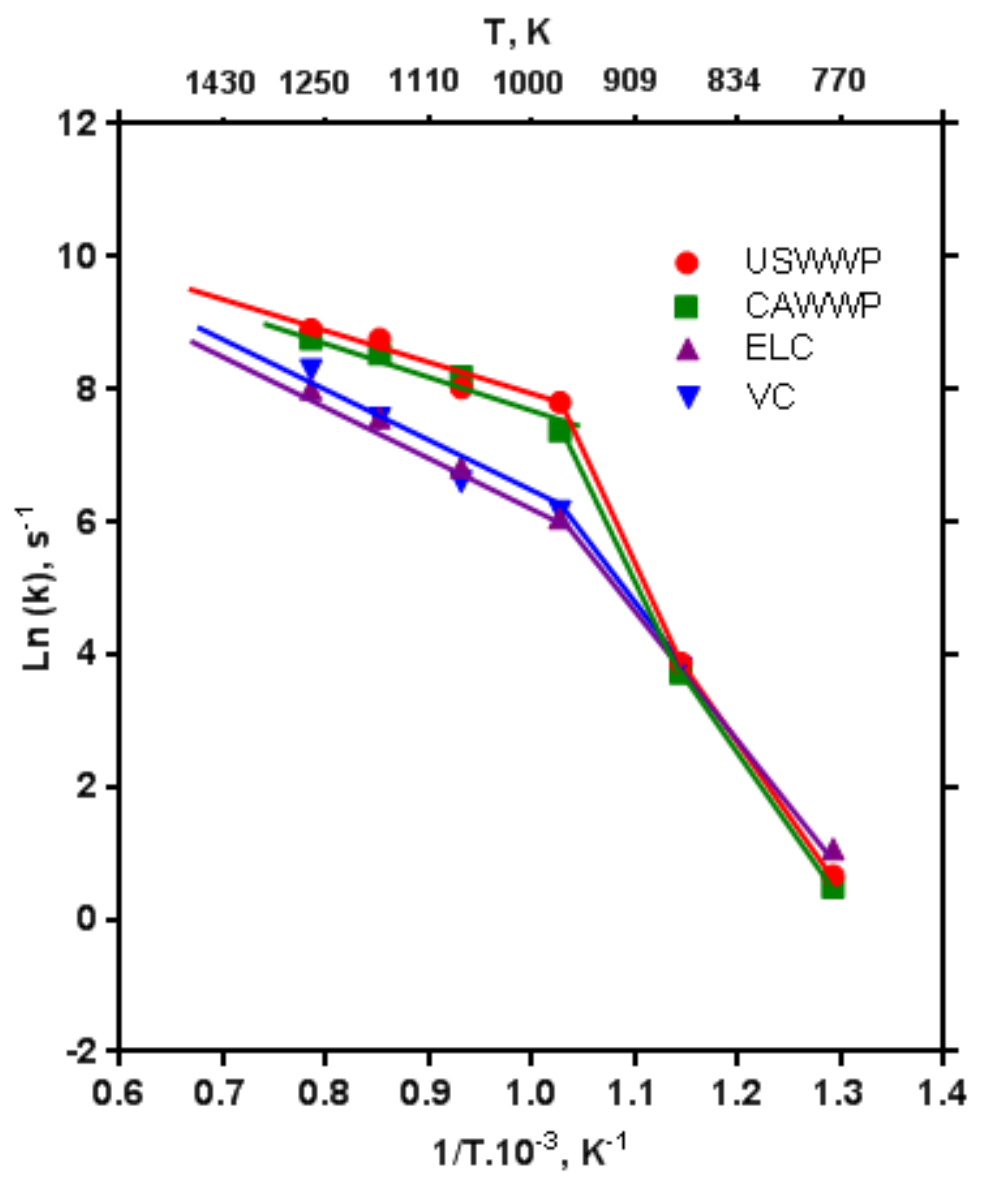

Fig. 10. Arrhenius plot of $\operatorname{Ln}(\mathrm{k})$ with reciprocal temperature.

The intrinsic activation energy and pre-exponential factor were calculated from the slop and intercept of the regression lines in the combustion Zone I. The results of the intrinsic activation energy $E_{m}$ and the pre-exponential factor $A$ in Zones I and II are summarized in Table 6.

As can be seen from Table 6, the intrinsic activation energy $E_{m}$ in the combustion Zone I of the USWWP and CAWWP are 180 and $182 \mathrm{~kJ} \mathrm{~mol}^{-1}$ respectively, and the pre-exponential factor was $2.85 \mathrm{E}+12$ and $3.04 \mathrm{E}+12$ for the USWWP and CAWWP, respectively. To date, the published work on biomass intrinsic reactivity is rarely found in the literature. Recent studies on wood pellets char reactivity under $\mathrm{CO}_{2}$ and steam gasification, used the Random Pore model (RPM) to calculate the kinetic parameters, and found a value for the $E_{m}$ 
220-251 kJ mol${ }^{-1}$ at temperatures in the range 873-1173 $\mathrm{K}[76,85]$. Yet, these results cannot be directly compared to the results of this study due to the different combustion conditions.

Table 5

Global intrinsic kinetic parameters

\begin{tabular}{|c|c|c|c|c|c|c|c|}
\hline & \multicolumn{3}{|c|}{ ZONE I } & \multicolumn{3}{|c|}{ ZONE II } & \multirow[b]{2}{*}{ Ell / El } \\
\hline & $\begin{array}{r}\mathrm{E}_{\mathrm{m}} \\
\mathrm{kJ} \mathrm{mol}^{-1}\end{array}$ & $A, s^{-1}$ & $\begin{array}{l}\mathrm{R}- \\
\text { Squared }\end{array}$ & $\begin{array}{c}\mathrm{E}_{\mathrm{n}} \\
\mathrm{kJ} \mathrm{mol}^{-1}\end{array}$ & $A, s^{-1}$ & $\begin{array}{l}\mathrm{R}- \\
\text { Squared }\end{array}$ & \\
\hline USWWP & $180 \pm 5$ & $2.85 E+12$ & 1 & $42 \pm 5$ & $3.87 \mathrm{E}+05$ & 0.9255 & 0.23 \\
\hline CAWWP & $182 \pm 5$ & $3.04 \mathrm{E}+12$ & 1 & $47 \pm 6$ & $6.33 E+05$ & 0.9960 & 0.26 \\
\hline ELC & $153 \pm 12$ & $6.15 E+10$ & 1 & $67 \pm 11$ & $1.79 E+06$ & 0.9960 & 0.44 \\
\hline VC & $167 \pm$ & $4.23 E+11$ & 1 & $75 \pm 9$ & $4.17 \mathrm{E}+07$ & 0.9629 & 0.45 \\
\hline
\end{tabular}

The ELC and VC have values of $E_{m} 153 \pm 3$ and $167 \pm 4 \mathrm{~kJ} \mathrm{~mol}^{-1}$, and the $A$ values are $6.15 \mathrm{E}+10$ and $4.23 \mathrm{E}+11$, respectively. These results are in a good agreement with the published data on the intrinsic coal char reactivity at atmospheric pressure of oxygen. The intrinsic activation energy $E_{m}$ of semi-anthracite was found to be $167 \mathrm{~kJ} \mathrm{~mol}^{-1}$ [86], knowing that the VC rank is considered as semi-anthracite, $134 \mathrm{~kJ} \mathrm{~mol}^{-1}$ for brown-coal char [14], 136

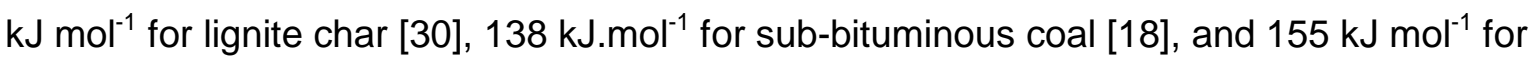
anthracite coal [39].

Although the values of the coal char $\mathrm{E}_{\mathrm{m}}$ are significantly lower than the biomass corresponding values, the higher values of the pre-exponential factors for the biomass chars appear to be inversely affecting the reaction rates, namely increasing the collision frequencies. Ultimately, the resultant reactivities are very similar as have been shown in Figure 10

In combustion Zone II, the higher reactivity of the biomass char is translated in a lower activation energy to burn compared to the coal chars. The values of $E_{a}$ for the USWWP, CAWWP, ELC and VC are 42, 47, 67 and $75 \mathrm{~kJ} \mathrm{~mol}^{-1}$, respectively. As shown in section 3.2.2, the relation between the activation energies in combustion Zone I and II has been derived. $E_{a}$ in Zone II is expected to be half of $E_{a}$ observed in Zone I [14, 20]. Experimentally, the biomass chars show a reduction in the activation energy to $0.25 \mathrm{E}_{\mathrm{m}}$ from Zone I to Zone II, while the ratio for the coal chars are like the theoretically expected values at 0.5 i.e. 0.44 and 0.45 for the ELC and the VC, respectively. These results suggest that the carbon oxidation in the biomass takes place at a notably lower diffusion limitation in combustion Zone II. 


\subsubsection{VALIDATION OF KINETIC PARAMETERS RESULTS}

In 1978 and 1982, Smith [2, 30] reviewed all the published data on intrinsic coal char reactivity. He unified the intrinsic reaction rate $\ddot{R}$ data on the basis of the oxygen pressure being $1 \mathrm{~atm}$ and plotted the intrinsic rate versus the reciprocal of the temperature. His plot exhibits a regression line of activation energy at $179 \mathrm{~kJ} \mathrm{~mol}^{-1}$ for chars of various ranks of coal. Although the differences in the pore size and surface area have been eliminated, the variation of the reactivity fell in the range of four orders of magnitude. He attributed these variations to the carbon structure and catalytic or inhibition effects of the impurities.

Accordingly, the reactivity of the chars in this study is recalculated at1atm oxygen pressure at $\mathrm{g} \mathrm{cm}^{-2} \mathrm{~s}^{-1}$ units to examine the comparability in the calculated intrinsic kinetic parameters, and pointed the results on Smith's plot. Fig. 11 presents the reactivities of four fuels, namely the USWWP, CAWWP, ELC and VC on the Smith reactivity plot. The temperature dependence of the four fuel chars is clearly shown in Fig. 11, and the alignment with the 179 $\mathrm{kJ} \mathrm{mol}^{-1}$ activation energy fitted line is notably good. This observation supports the assumptions made for the reaction orders in combustion Zones I and II. Moreover, all the char reactivity values were comparable in combustion Zone I. Also, the higher intrinsic reactivity of the biomass char in combustion Zone II reflects the lower activation energy than that of the coal char.

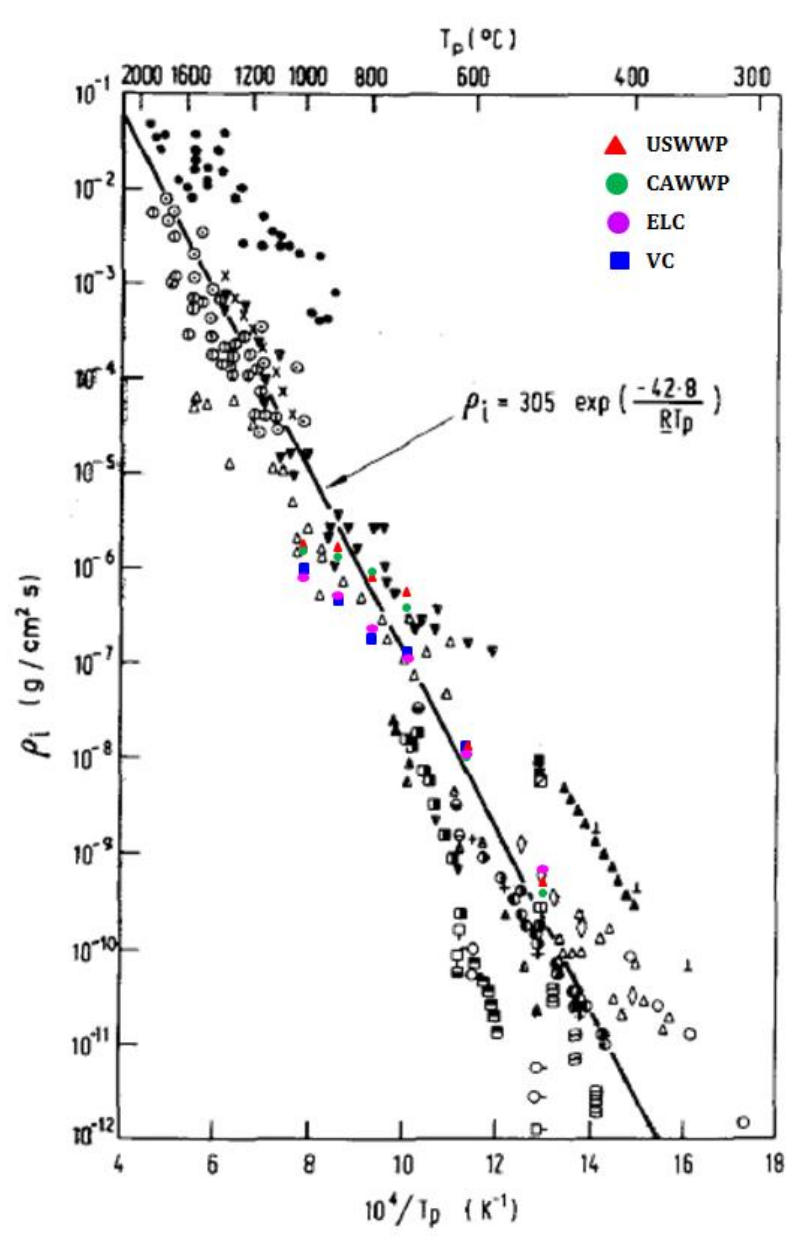


Fig. 11. Char intrinsic reactivity of USWWP, CAWWP, ELC and VC highlighted on Smith reactivity plot. (Ref: Smith 1982 [2])

\section{CONCLUSIONS}

The purpose of the current study was to investigate the pyrolysis behaviour and the char combustion kinetics of the wood pellets in comparison to coal under various temperatures. Although the char burn-off rate of the biomass was higher than that of the coal char, both types of fuel have shown similar intrinsic reactivities in the combustion Zone I (see Table 5reactivities in the temperature $873 \mathrm{~K}$ ). This proves the independence of intrinsic reactivity on the fuel type and rank. Conversely, in the combustion Zone II (in the temperature $1273 \mathrm{~K}$ ), the intrinsic biomass char combustion reactivity was 2-3 times higher than that of the coal chars due to the highly porous char structure produced at higher temperatures. Both biomass and coal chars exhibited an intermediate combustion zone between $973 \mathrm{~K}$ and $1173 \mathrm{~K}$.

The results of this study support the notion that the higher oxygen content of the biomass promotes early crosslinking during char combustion thus resulting in a higher porosity and surface area of the char produced. Equally, the high mineral content of the VC promotes the catalytic effect during the char combustion, therefore leading to a higher reactivity.

A noteworthy finding in this study is that the biomass can release $90 \%$ of its volatile matter in a low temperature such as $773 \mathrm{~K}$. While the coal releases less than $38-66 \%$ of its volatile matter in this temperature, thus the coal needs higher temperatures than a temperature $1273 \mathrm{~K}$ for complete devolatilization and this depends on the coal rank.

A limitation of this study is that the assumptions of the spherical shape and the pore model of the coal char applied on the biomass are not accurate to predict the actual activation energy in the combustion Zone II. Thus, it is recommended that further work be carried out to determine a better pore structure model, and the particle shape factor of the biomass to better predict the biomass char reactivity. Further experimental investigations of the gaseous products from the TGA experiments can improve the understanding of the complexity of the biomass pyrolysis and char combustion mechanisms.

\section{ACKNOWLEDGEMENTS}

The authors gratefully acknowledge the support of Dr. Mohammed Zandi to utilize the Combustion lab in the Chemical Engineering at the University of Sheffield. The help of Mr. James Grinham and Mr. Keith Penny at the analytical lab is also appreciated. This research 
did not receive any specific grant from funding agencies in the public, commercial, or not-forprofit sectors.

\section{REFERENCES}

[1] C. Di Blasi, F. Buonanno, C. Branca, Reactivities of some biomass chars in air, Carbon, 37 (1999) 1227-1238.

[2] I.W. Smith, The Combustion Rates of Coal Chars: A Review, in: Nineteenth International Symposium on Combustion, The Combustion Institute, 1982, pp. 1045-1065.

[3] S. Munir, S.S. Daood, W. Nimmo, A.M. Cunliffe, B.M. Gibbs, Thermal analysis and devolatilization kinetics of cotton stalk, sugar cane bagasse and shea meal under nitrogen and air atmospheres, Bioresource Technol, 100 (2009) 1413-1418.

[4] R. Findorak, M. Frohlichova, J. Legemza, L. Findorakova, Thermal degradation and kinetic study of sawdusts and walnut shells via thermal analysis, J Therm Anal Calorim, 125 (2016) 689-694.

[5] L.N. Samuelsson, M.U. Babler, E. Brannvall, R. Moriana, Pyrolysis of kraft pulp and black liquor precipitates derived from spruce: Thermal and kinetic analysis, Fuel Process Technol, 149 (2016) 275-284.

[6] R.K. Agrawal, Kinetics of Reactions Involved in Pyrolysis of Cellulose .2. The Modified KilzerBroido Model, Can J Chem Eng, 66 (1988) 413-418.

[7] J.A. Conesa, J.A. Caballero, A. Marcilla, R. Font, Analysis of Different Kinetic-Models in the Dynamic Pyrolysis of Cellulose, Thermochim Acta, 254 (1995) 175-192.

[8] F.J. Kilzer, A. Broido, Speculations on Nature of Cellulose Pyrolysis, Pyrodynamic, 2 (1965) 151-\&.

[9] J.J. Manya, E. Velo, L. Puigjaner, Kinetics of biomass pyrolysis: A reformulated three-parallelreactions model, Ind Eng Chem Res, 42 (2003) 434-441.

[10] C. Branca, A. Albano, C. Di Blasi, Critical evaluation of global mechanisms of wood devolatilization, Thermochim Acta, 429 (2005) 133-141.

[11] M.A. Martin-Lara, G. Blazquez, A. Ronda, M. Calero, Kinetic study of the pyrolysis of pine cone shell through non-isothermal thermogravimetry: Effect of heavy metals incorporated by biosorption, Renew Energ, 96 (2016) 613-624.

[12] W. Rukthong, Thanatawee, P., Sunphorka, A., Piumsumboon, P., and Chalermsinsuwan, B., Computation of Biomass Combustion Characteristic and Kinetic Parameters by Using

Thermogravimetric Analysis, Engineering Journal of Chulalongkorn University- Thiland, 19 (2015) 16.

[13] J.J. Murphy, C.R. Shaddix, Combustion kinetics of coal chars in oxygen-enriched environments, Combust Flame, 144 (2006) 710-729.

[14] R.J. Hamor, I.W. Smith, R.J. Tyler, Kinetics of Combustion of a Pulverized Brown Coal Char between 630 and 2200 Degrees K, Combust Flame, 21 (1973) 153-162.

[15] A.A. Lizzio, A. Piotrowski, L.R. Radovic, Effect of Oxygen-Chemisorption on Char Gasification Reactivity Profiles Obtained by Thermogravimetric Analysis, Fuel, 67 (1988) 1691-1695.

[16] J.M. Ranish, P.L. Walker, High-Pressure Studies of the Carbon-Oxygen Reaction, Carbon, 31 (1993) 135-141.

[17] J. Fermoso, M.V. Gil, C. Pevida, J.J. Pis, F. Rubiera, Kinetic models comparison for non-isothermal steam gasification of coal-biomass blend chars, Chem Eng J, 161 (2010) 276-284.

[18] R.H. Essenhigh, Rate-Equations for the Carbon-Oxygen Reaction - an Evaluation of the Langmuir Adsorption-Isotherm at Atmospheric-Pressure, Energy \& Fuels, 5 (1991) 41-46.

[19] D. Fortsch, Essenhigh, R.H., Schnell, U., and Hein K.R.G., On the application of the Thiele/Zeldovich Analysis to porous Carbon Combustion, Energy \& Fuels, 17 (2003) 901-906.

[20] R.H. Hurt, J.M. Calo, Semi-global intrinsic kinetics for char combustion modeling, Combust Flame, 125 (2001) 1138-1149.

[21] B.S. Haynes, T.G. Newbury, Oxyreactivity of carbon surface oxides, P Combust Inst, 28 (2000) 2197-2203.

[22] Q.L. Zhuang, T. Kyotani, A. Tomita, Desorption behavior of surface oxygen complexes on carbon in an inert gas and in 0-2-gasification atmosphere, Energy \& Fuels, 10 (1996) 169-172. 
[23] P.J. Ashman, B.S. Haynes, P.M. Nicholls, P.F. Nelson, Interactions of gaseous NO with char during the low-temperature oxidation of coal chars, P Combust Inst, 28 (2000) 2171-2179.

[24] D. Trommer, A. Steinfeld, Kinetic modeling for the combined pyrolysis and steam gasification of petroleum coke and experimental determination of the rate constants by dynamic thermogravimetry in the 500-1520 K range, Energy \& Fuels, 20 (2006) 1250-1258.

[25] L. Liu, Q.C. Liu, Y. Cao, W.P. Pan, The isothermal studies of char-CO2 gasification using the highpressure thermo-gravimetric method, J Therm Anal Calorim, 120 (2015) 1877-1882.

[26] Z. Niu, Liu, G., Yin, H., Wu, D. and Zhou, C., investigation of mechanism and kinetics of nonisothermal low temperature pyrolysis of prehydrous bituminous coal by in-situ FTIR, Fuel, 172 (2016) 1-10.

[27] P. Khare, B.P. Baruah, P.G. Rao, Application of chemometrics to study the kinetics of coal pyrolysis: A novel approach, Fuel, 90 (2011) 3299-3305.

[28] Y.B. Yang, V.N. Sharifi, J. Swithenbank, L. Ma, L.I. Darvell, J.M. Jones, M. Pourkashanian, A. Williams, Combustion of a single particle of biomass, Energy \& Fuels, 22 (2008) 306-316.

[29] C. Dupont, T. Nocquet, J.A. Da Costa, C. Verne-Tournon, Kinetic modelling of steam gasification of various woody biomass chars: Influence of inorganic elements, Bioresource Technol, 102 (2011) 9743-9748.

[30] I.W. Smith, Intrinsic Reactivity of Carbons to Oxygen, Fuel, 57 (1978) 409-414.

[31] N.M. Laurendeau, Heterogeneous Kinetics of Coal Char Gasification and Combustion, Prog Energ Combust, 4 (1978) 221-270.

[32] I.W. Smith, R.J. Tyler, Internal Burning of Pulverized Semi-Anthracite - Relation between Particle Structure and Reactivity, Fuel, 51 (1972) 312-\&.

[33] E.W. Thiele, Relation between catalytic activity and size of particle, Ind Eng Chem, 31 (1939) 916-920.

[34] A. Williams, M. Pourkashanian, J.M. Jones, The combustion of coal and some other solid fuels, P Combust Inst, 28 (2000) 2141-2162.

[35] A. Williams, R. Backreedy, R. Habib, J.M. Jones, M. Pourkashanian, Modelling coal combustion: the current position, Fuel, 81 (2002) 605-618.

[36] M. Gharebaghi, R.M.A. Irons, L. Ma, M. Pourkashanian, A. Pranzitelli, Large eddy simulation of oxy-coal combustion in an industrial combustion test facility, Int J Greenh Gas Con, 5 (2011) S100S110.

[37] J. Hong, W.C. Hecker, T.H. Fletcher, Modeling high-pressure char oxidation using Langmuir kinetics with an effectiveness factor, P Combust Inst, 28 (2000) 2215-2223.

[38] J.H. Hong, W.C. Hecker, T.H. Fletcher, Improving the accuracy of predicting effectiveness factors for mth order and Langmuir rate equations in spherical coordinates, Energy \& Fuels, 14 (2000) 663670.

[39] L. Alvarez, M. Gharebaghi, M. Pourkashanian, A. Williams, J. Riaza, C. Pevida, J.J. Pis, F. Rubiera, CFD modelling of oxy-coal combustion in an entrained flow reactor, Fuel Process Technol, 92 (2011) 1489-1497.

[40] J. Adanez, L.F. de Diego, F. Garcia-Labiano, A. Abad, J.C. Abanades, Determination of biomass char combustion reactivities for FBC applications by a combined method, Ind Eng Chem Res, 40 (2001) 4317-4323.

[41] X.Y. Gao, Y.N. Zhang, B.X. Li, Y.J. Zhao, B.C. Jiang, Determination of the intrinsic reactivities for carbon dioxide gasification of rice husk chars through using random pore model, Bioresource Technol, 218 (2016) 1073-1081.

[42] M.R. Khan, Reactivity of low-Temperature Chars: Significance of char active surface area as a reactivity parameter, in: 6th Annual Gasification Contractors Meeting, Morgantown, West Virginia, 1986.

[43] C. Branca, C. Di Blasi, Combustion Kinetics of Secondary Biomass Chars in the Kinetic Regime, Energy \& Fuels, 24 (2010) 5741-5750.

[44] Q. Zhu, J.M. Jones, A. Williams, K.M. Thomas, The predictions of coal/char combustion rate using an artificial neural network approach, Fuel, 78 (1999) 1755-1762. 
[45] S.P. Nandi, V. Ramadass, P.L. Walker, Changes in the Ultrafine Structure of Anthracites Upon Heat Treatment, Carbon, 2 (1964) 199-210.

[46] R.I. Razouk, F.Z. Saleeb, A.M. Youssef, Effect of Thermal Treatment on Surface Area of Coal, Carbon, 6 (1968) 325-\&.

[47] M.L. Chan, J.M. Jones, M. Pourkashanian, A. Williams, The oxidative reactivity of coal chars in relation to their structure, Fuel, 78 (1999) 1539-1552.

[48] J.M. Jones, M. Pourkashanian, C.D. Rena, A. Williams, Modelling the relationship of coal structure to char porosity, Fuel, 78 (1999) 1737-1744.

[49] J.L. Yu, V. Strezov, J. Lucas, T. Wall, Swelling behaviour of individual coal particles in the single particle reactor, Fuel, 82 (2003) 1977-1987.

[50] J.L. Yu, J. Lucas, V. Strezov, T. Wall, Swelling and char structures from density fractions of pulverized coal, Energy \& Fuels, 17 (2003) 1160-1174.

[51] J.B. Howard, Essenhig.Rh, Pyrolysis of Coal Particles in Pulverized Fuel Flames, Ind Eng Chem Proc Dd, 6 (1967) 74-\&.

[52] M. Ottaway, Use of Thermogravimetry for Proximate Analysis of Coals and Cokes, Fuel, 61 (1982) 713-716.

[53] Satterfi.Cn, D.H. Cortez, Mass Transfer Characteristics of Woven-Wire Screen Catalysts, Ind Eng Chem Fund, 9 (1970) 613-\&.

[54] G.D. Sergeant, I.W. Smith, Combustion Rate of Bituminous Coal Char in Temperature-Range 800 to $1700 \mathrm{~K}$, Fuel, 52 (1973) 52-57.

[55] R.H. Essenhigh, Influence of Initial Particle Density on the Reaction Mode of Porous Carbon Particles, Combust Flame, 99 (1994) 269-279.

[56] H. Gan, P.L. Walker, S.P. Nandi, Nature of Porosity in American Coals, Fuel, 51 (1972) 272-\&.

[57] A.W. Harding, S.D. Brown, K.M. Thomas, Release of NO from the combustion of coal chars, Combust Flame, 107 (1996) 336-350.

[58] A. Arenillas, R.I. Backreedy, J.M. Jones, J.J. Pis, A. Pourkashanian, F. Rubiera, A. Williams, Modelling of NO formation in the combustion of coal blends, Fuel, 81 (2002) 627-636.

[59] M.S. Masnadi, R. Habibi, J. Kopyscinski, J.M. Hill, X.T. Bi, C.J. Lim, N. Ellis, J.R. Grace, Fuel characterization and co-pyrolysis kinetics of biomass and fossil fuels, Fuel, 117 (2014) 1204-1214.

[60] W. Suliman, J.B. Harsh, N.I. Abu-Lail, A.M. Fortuna, I. Dallmeyer, M. Garcia-Perez, Modification of biochar surface by air oxidation: Role of pyrolysis temperature, Biomass Bioenerg, 85 (2016) 1-11. [61] D. Lopez-Gonzalez, M. Fernandez-Lopez, J.L. Valverde, L. Sanchez-Silva, Gasification of lignocellulosic biomass char obtained from pyrolysis: Kinetic and evolved gas analyses, Energy, 71 (2014) 456-467.

[62] F. Vallejos-Burgos, N. Diaz-Perez, A. Silva-Villalobos, R. Jimenez, X. Garcia, L.R. Radovic, On the structural and reactivity differences between biomass- and coal-derived chars, Carbon, 109 (2016) 253-263.

[63] S.A. Halim, J. Swithenbank, Characterisation of Malaysian wood pellets and rubberwood using slow pyrolysis and microwave technology, J Anal Appl Pyrol, 122 (2016) 64-75.

[64] I.W. Smith, Kinetics of Combustion of Size-Graded Pulverized Fuels in Temperature-Range 12002270 Degrees K, Combust Flame, 17 (1971) 303-\&.

[65] L.M. Lu, V. Sahajwalla, D. Harris, Coal char reactivity and structural evolution during combustion - Factors influencing blast furnace pulverized coal injection operation, Metall Mater Trans B, 32 (2001) 811-820.

[66] K. Matsuoka, H. Akiho, W.C. Xu, R. Gupta, T.F. Wall, A. Tomita, The physical character of coal char formed during rapid pyrolysis at high pressure, Fuel, 84 (2005) 63-69.

[67] J. Guo, A.C. Lua, Characterization of chars pyrolyzed from oil palm stones for the preparation of activated carbons, J Anal Appl Pyrol, 46 (1998) 113-125.

[68] S.F. Vaughn, J.A. Kenar, F.J. Eller, B.R. Moser, M.A. Jackson, S.C. Peterson, Physical and chemical characterization of biochars produced from coppiced wood of thirteen tree species for use in horticultural substrates, Ind Crop Prod, 66 (2015) 44-51. 
[69] J. Pastor-Villegas, J.F. Pastor-Valle, J.M.M. Rodriguez, M.G. Garcia, Study of commercial wood charcoals for the preparation of carbon adsorbents, J Anal Appl Pyrol, 76 (2006) 103-108.

[70] ECN, Biochar Beech wood (\#3518), in: ECN Phyllis classification, ECN, Netherlands, 2015.

[71] ECN, Biochar from a blend of greenhouse waste (tomato leaves and stems) and clean wood (\#3522), in: L. Fryda (Ed.) ECN Phyllis classification, ECN, Netherlands, 2015.

[72] ECN, Biochar from greenhouse waste (pepper residues) 400/60/0 (\#3536), in: L. Fryda (Ed.) ECN Phyllis classification, ECN, Netherlands, 2015.

[73] ECN, Biochar from greenhouse waste (pepper residues) under gasification (1) (\#3519), in: L. Fryda (Ed.) ECN Phyllis classification, ECN, Netherlands, 2015.

[74] ECN, Biochar from greenhouse waste (pepper residues) 600/60/0 (\#3535), in: L. Fryda (Ed.) ECN Phyllis classification, ECN, Netherlands, 2015.

[75] ECN, Biochar from greenhouse waste (pepper residues) under gasification (2) (\#3520), in: L. Fryda (Ed.) ECN Phyllis classification, ECN, Netherlands, 2015.

[76] N. Ellis, M.S. Masnadi, D.G. Roberts, M.A. Kochanek, A.Y. llyushechkin, Mineral matter interactions during co-pyrolysis of coal and biomass and their impact on intrinsic char co-gasification reactivity, Chem Eng J, 279 (2015) 402-408.

[77] S.K. Mookherjea, B.K. Mazumdar, Some Aspects of Low Temperature Pyrolysis Behaviour of Coal, Fuel, 48 (1969) 277-+.

[78] J.L. Johnson, Relationships between Coal-Char Gasification Reactivities and Physical and Chemical Coal and Coal-Char Properties, Abstr Pap Am Chem S, 170 (1975) 30-30.

[79] K. Tomkow, T. Siemieniewska, F. Czechowski, A. Jankowska, Formation of Porous Structures in Activated Brown-Coal Chars Using O-2, Co2 and H2O as Activating Agents, Fuel, 56 (1977) 121-124. [80] P.R. Solomon, G.V. Deshpande, M.A. Serio, Crosslinking Reactions in Coal Pyrolysis, Abstr Pap Am Chem S, 195 (1988) 99-Fuel.

[81] P. Nanou, H.E.G. Murillo, W.P.M. van Swaaij, G. van Rossum, S.R.A. Kersten, Intrinsic reactivity of biomass-derived char under steam gasification conditions-potential of wood ash as catalyst, Chem Eng J, 217 (2013) 289-299.

[82] S.E. Smith, R.C. Neavel, E.J. Hippo, R.N. Miller, Dtga Combustion of Coals in the Exxon Coal Library, Fuel, 60 (1981) 458-462.

[83] S.S. Daood, S. Munir, W. Nimmo, B.M. Gibbs, Char oxidation study of sugar cane bagasse, cotton stalk and Pakistani coal under 1\% and 3\% oxygen concentrations, Biomass Bioenerg, 34 (2010) 263271.

[84] B.C. Young, I.W. Smith, The Combustion of Loy Yang Brown Coal Char, Combust Flame, 76 (1989) 29-35.

[85] L.T. Lin, M. Strand, Investigation of the intrinsic $\mathrm{CO} 2$ gasification kinetics of biomass char at medium to high temperatures, Appl Energ, 109 (2013) 220-228.

[86] I.W. Smith, The Kinetics of Combustion of Pulverized Semi-Anthracite in Temperature-Range 1400-2200 Degrees K, Combust Flame, 17 (1971) 421-\&. 